\title{
Comparison of Tropical Cyclone Activities over the Western North Pacific in CORDEX-East Asia Phase I and II Experiments
}

\author{
Minkyu Lee, ${ }^{\mathrm{a}}$ Dong-Hyun Cha, ${ }^{\mathrm{a}}$ Myoung-Seok Suh, ${ }^{\mathrm{b}}$ Eun-Chul Chang, ${ }^{\mathrm{b}}$ Joong-Bae Ahn, ${ }^{\mathrm{c}}$ \\ SEUNG-KI Min, ${ }^{\mathrm{d}}$ AND Young-HwA BYun ${ }^{\mathrm{e}}$ \\ ${ }^{a}$ Ulsan National Institute of Science and Technology, Ulsan, South Korea \\ ${ }^{\mathrm{b}}$ Kongju National University, Gongju, South Korea \\ ${ }^{\mathrm{c}}$ Pusan National University, Busan, South Korea \\ ${ }^{\mathrm{d}}$ Pohang University of Science and Technology, Pohang, South Korea \\ ${ }^{\mathrm{e}}$ National Institute of Meteorological Sciences, Seogwipo, South Korea
}

(Manuscript received 31 December 2019, in final form 26 August 2020)

\begin{abstract}
This study evaluated tropical cyclone (TC) activity simulated by two regional climate models (RCMs) incorporated in the Coordinated Regional Climate Downscaling Experiment (CORDEX) framework with two different horizontal resolutions. Evaluation experiments with two RCMs (RegCM4 and MM5) forced by reanalysis data were conducted over the CORDEX-East Asia domain for phases I and II. The main difference between phases I and II is horizontal resolution (50 and $25 \mathrm{~km}$ ). The 20-yr (1989-2008) mean performances of the experiments were investigated in terms of TC genesis, track, intensity, and TC-induced precipitation. In general, the simulated TC activities over the western North Pacific (WNP) varied depending on the model type and horizontal resolution. For both models, higher horizontal resolution improved the simulation of TC tracks near the coastal regions of East Asia, whereas the coarser horizontal resolution led to underestimated TC genesis compared with the best track data because of greater convective precipitation and enhanced atmospheric stabilization. In addition, the increased horizontal resolution prominently improved the simulation of TCs landfalling in East Asia and associated precipitation around coastal regions. This finding implies that high-resolution RCMs can improve the simulation of TC activities over the WNP (i.e., added value by increasing model resolution); thus, they have an advantage in climate change assessment studies.
\end{abstract}

KEYWORDS: Pacific Ocean; Tropical cyclones; Climatology; Climate models; Model evaluation/performance; Regional models

\section{Introduction}

Tropical cyclones (TCs) are among the most destructive natural disasters in the world and are accompanied by strong wind gusts, heavy precipitation, and storm surge. Around 90 TCs occur worldwide in the various basins every year, of which about 25 to 30 occur in the western North Pacific (WNP). Strong TCs develop more frequently in the WNP than in other basins (Mendelsohn et al. 2012; Peduzzi et al. 2012; Woodruff et al. 2013). Moreover, stronger TCs have struck the East Asian countries in the recent decade (Park et al. 2014). Therefore, accurate prediction of TC activity is a crucial issue because of the extensive casualties and property damage caused by TCs in East Asia (Park et al. 2015; Zhang et al. 2009).

Global climate models (GCMs) can reproduce TC-like structures comparable with observations to some extent (Bengtsson et al. 1982; Camargo 2013; Manabe et al. 1970; Vitart et al. 1997). Nevertheless, it is difficult for GCMs to realistically simulate the intensity and size of a TC because of the coarser horizontal resolution. To resolve these drawbacks, high-resolution GCMs have been used in many previous studies (Bacmeister et al. 2018; Gualdi et al. 2008; H.-S. Kim et al. 2014; Manganello et al. 2012; Oouchi et al. 2006; Wehner et al. 2014). However, a compromise between the model resolution, simulation period, and physical complexity is inevitable

Corresponding author: Dong-Hyun Cha, dhcha@unist.ac.kr because of the limitations of computational resources (Murakami et al. 2013; Strachan et al. 2013). To complement the shortcomings of GCMs, dynamical downscaling of GCMs with higher-resolution regional climate models (RCMs) has been widely used to study TC climatology and future projections, because this method can reproduce more detailed structures or intensities of TCs in a region of interest (Barcikowska et al. 2017; Camargo et al. 2007; Cha et al. 2011; Emanuel et al. 2008; Knutson et al. 2007; Lee et al. 2013; Redmond et al. 2015; Zhang and Wang 2017).

However, using a single RCM may cause inherent uncertainties and systematic errors (Emanuel 2013). To reduce the disadvantages of using a single RCM, multi-RCMs have been used for the dynamical downscaling of GCMs (Christensen et al. 2007; Frei et al. 2006; G. Kim et al. 2014). For instance, the Coordinated Regional Climate Downscaling Experiment (CORDEX) organized by the World Climate Research Programme (WCRP) has been conducted to produce a qualitycontrolled dataset of climate change information generated by a multi-GCM/RCM matrix (Giorgi et al. 2009). CORDEX has standard settings for 14 continent-scale domains of interest to facilitate intermodel comparison (Zou et al. 2016). CORDEX-East Asia is the East Asian branch of the CORDEX initiative. The CORDEX-East Asia domain includes most East Asian countries, India, and the western Pacific Ocean, which is appropriate to simulate TCs over the WNP. Phase I (EAS44) covering the East Asian domain with a 50-km horizontal 
resolution was already completed, and phase II (EAS22) has recently been conducted at $25-\mathrm{km}$ horizontal resolution. In South Korea, five RCMs have been incorporated in the CORDEX-East Asia project in each phase [the HadGEM3RA, Mesoscale Model version 5 (MM5), Regional Climate Model version 4.0 (RegCM4), Weather Research and Forecasting version 3.7 (WRF), and Global/Regional Integrated Model system (GRIMs) for phase I, which was replaced with the Consortium for Small-scale Modeling (COSMO)-Climate Limited-Area Modeling (CCLM) for phase II].

To generate reliable future climate change information for decision-making procedures, RCM performance should be evaluated for the present climate before the RCM is used for future projections (J. Kim et al. 2014; Oh et al. 2014; Park et al. 2016; Suh et al. 2012). Many studies have focused on precipitation and temperature in the CORDEX-East Asia domain (Choi and Ahn 2017; Huang et al. 2015; Oh et al. 2011, 2014; Park et al. 2013; Tang et al. 2017; Wang et al. 2013; Zou et al. 2016). However, only a few studies have investigated TC activities in the CORDEX-East Asia domain (Jin et al. 2016; Shen et al. 2017, 2019). For example, Jin et al. (2016) evaluated simulated TC activities over the WNP from the five RCMs in CORDEX phase I, and Shen et al. (2019) conducted a test of the sensitivity of simulated TCs to five convection schemes using the WRF model forced by reanalysis data under the CORDEX-East Asia phase II framework. However, no studies have evaluated TC activity over the WNP simulated by the MM5 and $\mathrm{RegCM} 4$ in the CORDEX phase II framework and compared simulated TC activity between phases I and II.

One of the advantages of RCMs is added value such as improved simulations of extreme events and mesoscale features, which cannot be resolved by GCMs because of the relatively coarse model resolution. Increasing model resolution can be a crucial issue in regional climate modeling; therefore, the effects of model resolution on TC simulation have been investigated in the last few decades (Bhaskar Rao et al. 2009; Gualdi et al. 2008; Jin et al. 2014; Murakami and Sugi 2010; Walsh et al. 2013; Wehner et al. 2015; Zhou and Mu 2012). In previous studies, higher horizontal resolution in models could more reasonably reproduce the characteristic of TCs such as track density, duration, and intensity (Fuentes-Franco et al. 2017; Wehner et al. 2014). In addition, Strachan et al. (2013) highlighted that increased model resolution had a notable impact on storm intensity, but less significant impact on TC frequency. A number of previous studies have shown the importance of added value by increasing model resolution in RCM simulations (Bozkurt et al. 2019; Di Luca et al. 2012; Kanamitsu and DeHaan 2011; Lucas-Picher et al. 2012). Similarly, in this study, the added value of finer horizontal resolution is evaluated for TC simulation over the WNP compared with coarser horizontal resolution.

In this study, the performances of two RCMs (RegCM4 and MM5) incorporated in CORDEX-East Asia phase I as well as phase II are evaluated, and the impact of the increased horizontal resolution is also investigated in terms of overall TC activity and the characteristics of TCs landfalls in coastal regions of East Asia. The dataset, models, and analysis methods are described in section 2 . In section 3a, we discuss TC activity in terms of TC formation, tracks, frequency, duration, and intensity. In section 3b, TC-induced precipitation is presented based on the first landfalls of TCs. Finally, section 4 provides a summary of the results and discussion.

\section{Data and methods}

\section{a. Data}

In this study, the best track dataset from the Regional Specialized Meteorological Center (RSMC) Tokyo-Typhoon Center (http://www.jma.go.jp/en/typh/) was used to evaluate the performance of each model. It contains 6-hourly latitude, longitude, minimum central pressure, and maximum wind speed (10-min average maximum winds) data. TC genesis is defined as the moment that a tropical depression changes into a tropical storm (i.e., wind speed greater than $17 \mathrm{~m} \mathrm{~s}^{-1}$ ). In addition, all categories of TCs except tropical depressions were included to examine the changes in TC track density (i.e., tropical storms, severe tropical storms, and typhoons). The observed precipitation data were obtained from the Asian Precipitation-Highly Resolved Observational Data Integration Toward Evaluation (APHRODITE) $0.25^{\circ}$ daily dataset (Yatagai et al. 2012), which was used to evaluate the performance of precipitation simulation induced by TCs.

\section{b. Models}

Considering model consistency between CORDEX phases I and II and the performance for TC simulation, we selected two RCMs (RegCM4 and MM5) for the dynamical downscaling of the reanalysis data. The HadGEM3-RA model was excluded because of its unreasonable underestimation of TC activity over most of the WNP compared with the best track data (Jin et al. 2016). The WRF was excepted because there were significant differences in simulated TC activities between phases I and II. These differences were mainly attributed to the replacement of the convection scheme, which had significant impacts on the simulation of TC track and intensity (Ma and Tan 2009; Mohandas and Ashrit 2014; Shen et al. 2019; Shepherd and Walsh 2017). Also, GRIMs in phase I and CCLM in phase II were also excluded because of the inconsistency of the models.

The ERA-Interim dataset with a spatial resolution of $1.5^{\circ} \times$ $1.5^{\circ}$ was used as the large-scale forcing of both RCMs (Dee et al. 2011). Spectral nudging (Cha et al. 2016; von Storch et al. 2000) was applied to both RCMs to minimize the systematic errors in the long-term simulations induced by deviation between large-scale forcing and model solutions. The nudging was only applied for horizontal wind fields and the cutoff wavelengths for the large-scale regimes were assumed to be $1000-1100 \mathrm{~km}$. The model computational domains and configuration of each RCM is described in Fig. 1 and Table 1. Most of the dynamics and physics of EAS-44 (phase I) and EAS-22 (phase II) were similar, but there was a significant difference in the horizontal resolution (EAS-44: $50 \mathrm{~km}$; EAS-22: $25 \mathrm{~km}$ ) and vertical level in only RegCM4. However, vertical level had a minor impact on TC simulation compared to the horizontal resolution in RegCM4 (not shown). Hereafter, the RegCM4 


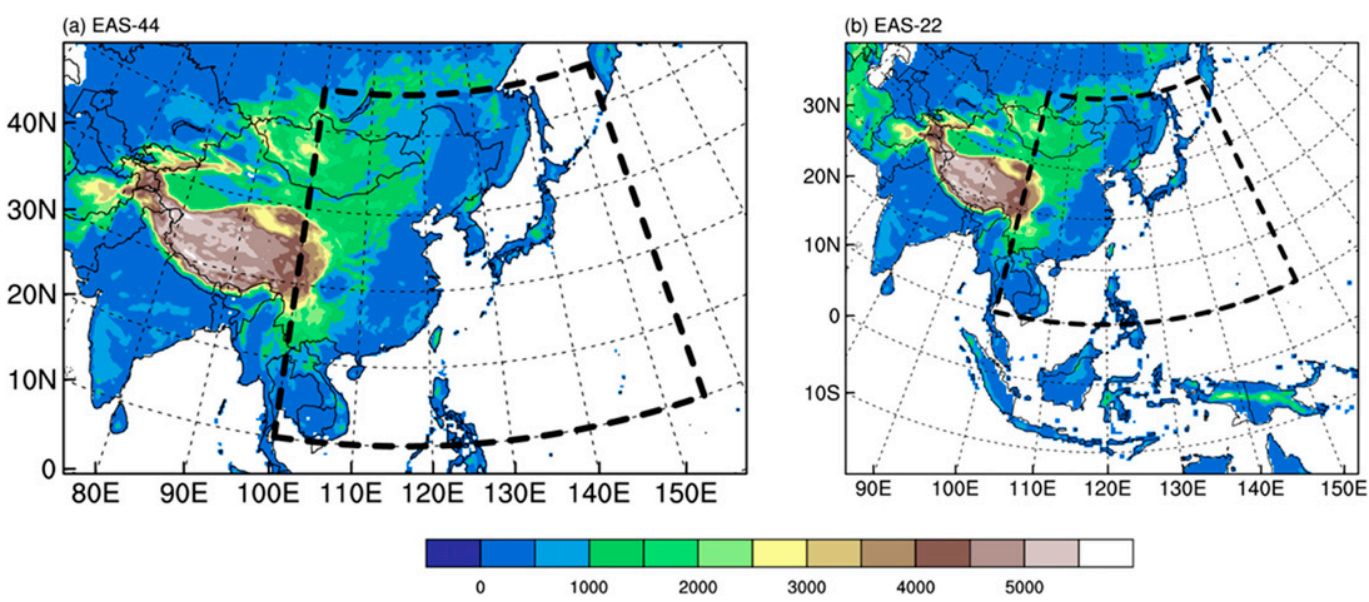

FIG. 1. CORDEX-East Asia domains of (a) EAS-44 and (b) EAS-22 with topography (m). Computational domains are the whole rectangle boxes, and black dashed lines indicate analysis domains.

(MM5) of phase I at 50-km horizontal resolution is referred to as RegCM4_EAS44 (MM5_EAS44), and the RegCM4 (MM5) of phase II at $25-\mathrm{km}$ horizontal resolution is referred to as RegCM4_EAS22 (MM5_EAS22). The analysis domain was defined as $10^{\circ}-55^{\circ} \mathrm{N}, 100^{\circ}-155^{\circ} \mathrm{E}$, which covers $85 \%$ of $\mathrm{TC}$ activity over the WNP. It is one of the drawbacks of the CORDEX-East Asia domain for TC simulation. In addition, the simulation periods for EAS22 and EAS44 were conducted continuously from January to December in 1979-2013 and 1989-2008, respectively. Therefore, the analysis period was set as 20 years (1989-2008) of the June to November (JJASON) period when most TCs over the WNP occur.

\section{c. Methods}

TCs simulated by the RCMs were identified by the following detection and tracking method modified from Cha et al. (2011) and Jin et al. (2016): 1) The potential storm is a local minimum of sea level pressure. 2) The searching radius around the minimum of sea level pressure is $250 \mathrm{~km}$. 3) The maximum sustained wind speed exceeds $17 \mathrm{~m} \mathrm{~s}^{-1}$ in searching radius. 4) The relative vorticity maximum at $850 \mathrm{hPa}$ exceeds $5 \times 10^{-5} \mathrm{~s}^{-1}$ in searching radius. 5) At 300,500 , and $700 \mathrm{hPa}$, the sum of the temperature deviations exceeds $2 \mathrm{~K}$ in searching radius. 6) The maximum sustained wind speed at $850 \mathrm{hPa}$ is larger than that at $300 \mathrm{hPa}$ in searching radius. 7) The lifetime of the TC is longer than 2 days. 8) Tracks are traced from these identified potential storms.

TC genesis and track densities were calculated to evaluate the TC simulation performance, and were displayed by binning the latitude and longitude positions into $2.5^{\circ} \times 2.5^{\circ}$ grid boxes; this process has previously been applied for the binning of TC data (Ho et al. 2013; M. Lee et al. 2019). When a TC migrated within the same grid point, the genesis and track density were computed only once.

The power dissipation index (PDI) indicates the potential destructiveness of a TC, and is integrated from the cube of the maximum sustained wind speed over the lifetime of the TC, defined by the following equation (Emanuel 2005):

$$
\mathrm{PDI}=\int_{0}^{\tau} V_{\max }^{3} d t
$$

TABLE 1. The configurations of RegCM4 and MM5.

\begin{tabular}{|c|c|c|c|c|}
\hline & \multicolumn{2}{|c|}{ RegCM4 } & \multicolumn{2}{|l|}{ MM5 } \\
\hline & EAS-22 & EAS-44 & EAS-22 & EAS-44 \\
\hline Institute & $\begin{array}{c}\text { Kongju National } \\
\text { University }\end{array}$ & $\begin{array}{c}\text { Kongju National } \\
\text { University }\end{array}$ & $\begin{array}{l}\text { Ulsan National Institute of } \\
\text { Science and Technology }\end{array}$ & $\begin{array}{c}\text { Seoul National } \\
\text { University }\end{array}$ \\
\hline Dynamics framework & \multicolumn{2}{|c|}{ Hydrostatic } & \multicolumn{2}{|c|}{ Nonhydrostatic } \\
\hline Map projection & \multicolumn{4}{|c|}{ Lambert conformal } \\
\hline $\begin{array}{l}\text { Horizontal resolution and } \\
\text { dimensions }\end{array}$ & $25 \mathrm{~km}(396 \times 251)$ & $50 \mathrm{~km}(241 \times 195)$ & $25 \mathrm{~km}(405 \times 260)$ & $50 \mathrm{~km}(232 \times 196)$ \\
\hline Vertical levels & 23 & 18 & 24 & 24 \\
\hline Convection & \multicolumn{2}{|c|}{ Emanuel (1991) } & \multicolumn{2}{|c|}{ Kain (2004) } \\
\hline Microphysics & \multicolumn{2}{|c|}{ Pal et al. (2000) } & \multicolumn{2}{|c|}{ Reisner et al. (1998) } \\
\hline PBL & \multicolumn{2}{|c|}{ Holtslag et al. (1990) } & \multicolumn{2}{|c|}{ Hong et al. (2006) } \\
\hline Reference & \multicolumn{2}{|c|}{ Giorgi et al. (2012) } & \multicolumn{2}{|c|}{ Lee et al. (2004) } \\
\hline $\begin{array}{l}\text { Initial and boundary } \\
\text { conditions }\end{array}$ & \multicolumn{4}{|c|}{ ERA-Interim } \\
\hline Analysis period & \multicolumn{4}{|c|}{ 1989-2008 (20 yr), June to November (JJASON) } \\
\hline
\end{tabular}



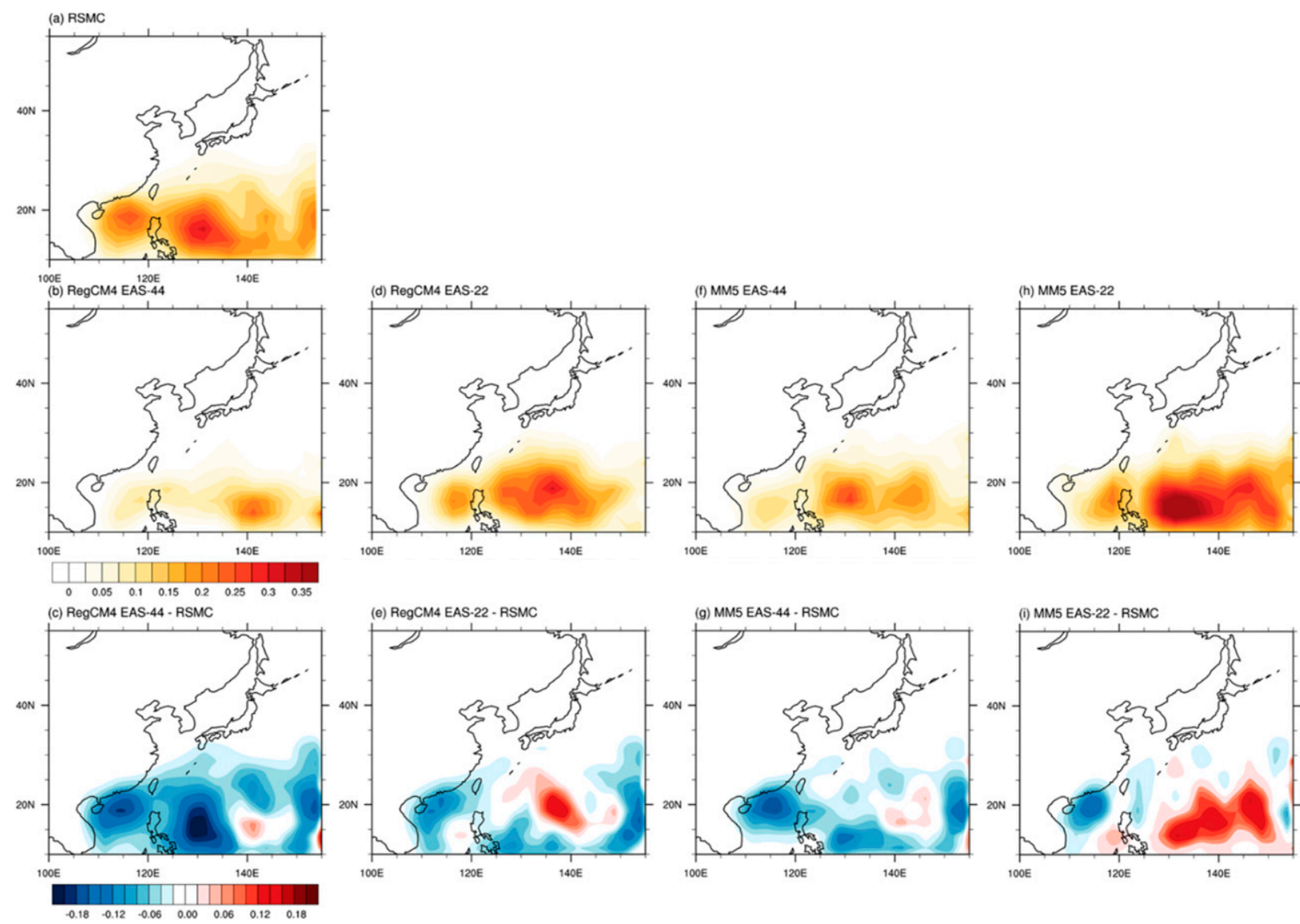

FIG. 2. Climatological mean of TC genesis density in the (a) RSMC, (b),(d) RegCM4, and (f),(h) MM5, and (c),(e),(g),(i) difference between RSMC and each model during 20 years (1989-2008).

where $V_{\max }$ and $\tau$ indicate the maximum sustained wind speed and the lifetime of the storm, respectively. The lifetime maximum intensity (LMI) was defined as the strongest maximum sustained wind speed during the whole lifetime of the TC.

We also investigated the impact of horizontal resolution on the simulation performance regarding the characteristics of the first landfall of TCs and TC-induced precipitation. The characteristics of the first landfall of TCs indicate the frequency, intensities, and positions when TCs makes their first landfalls during the entire life cycle. In defining TC-induced precipitation, there was an inconsistency problem of temporal resolution between TC best track data (6-hourly) and APHRODITE data (daily). Therefore, to minimize this inconsistency, TCinduced precipitation was calculated differently based on the TC landfall time. TC-induced precipitation was calculated as 1) total precipitation for four days ( $48 \mathrm{~h}$ before landfall to $48 \mathrm{~h}$ after) if landfall occurred at 0000 UTC, 2) total precipitation for four days ( $54 \mathrm{~h}$ before landfall to $42 \mathrm{~h}$ after it) if landfall occurred at 0600 UTC, 3) total precipitation for three days ( $36 \mathrm{~h}$ before landfall to $36 \mathrm{~h}$ after it) if landfall occurred at $1200 \mathrm{UTC}$, or 4) total precipitation for four days ( $42 \mathrm{~h}$ before landfall to $54 \mathrm{~h}$ after it) if landfall occurred at 1800 UTC. TCinduced precipitation was calculated within a radius of $10^{\circ}$ from the TC center. However, some biases could occur, since there are limitations with respect to inconsistency of temporal resolution.

\section{Results}

\section{a. Analysis of TC activity}

TC activity was analyzed to examine the performance of each model and the effect of horizontal resolution, focusing on TC genesis, tracks, and intensity. Figure 2 shows the $20-y r$ climatological mean of TC genesis density during the analysis period. In the RSMC best track data, the maximum TC genesis density was found near the Philippine Sea (PS; $10^{\circ}-20^{\circ} \mathrm{N}, 125^{\circ}-$ $135^{\circ} \mathrm{E}$ ) and the South China Sea (SCS; $\left.10^{\circ}-20^{\circ} \mathrm{N}, 110^{\circ}-120^{\circ} \mathrm{E}\right)$. The RegCM4_EAS44 underestimated TC genesis over both the PS and SCS compared with the best track data. Furthermore, TC genesis over the SCS was scarcely captured, and that over the PS was shifted eastward compared with the best track data. As the horizontal resolution of the RegCM4 increased to $25 \mathrm{~km}$ (i.e., EAS22), TC genesis was prominently improved since higher resolution is capable of resolving finer-scale TC precursors and thus more favorable TC genesis environmental conditions. However, it was still underestimated over the SCS and the eastern part of the domain $\left(10^{\circ}-25^{\circ} \mathrm{N}, 145^{\circ}-150^{\circ} \mathrm{E}\right)$. The MM5_EAS44 

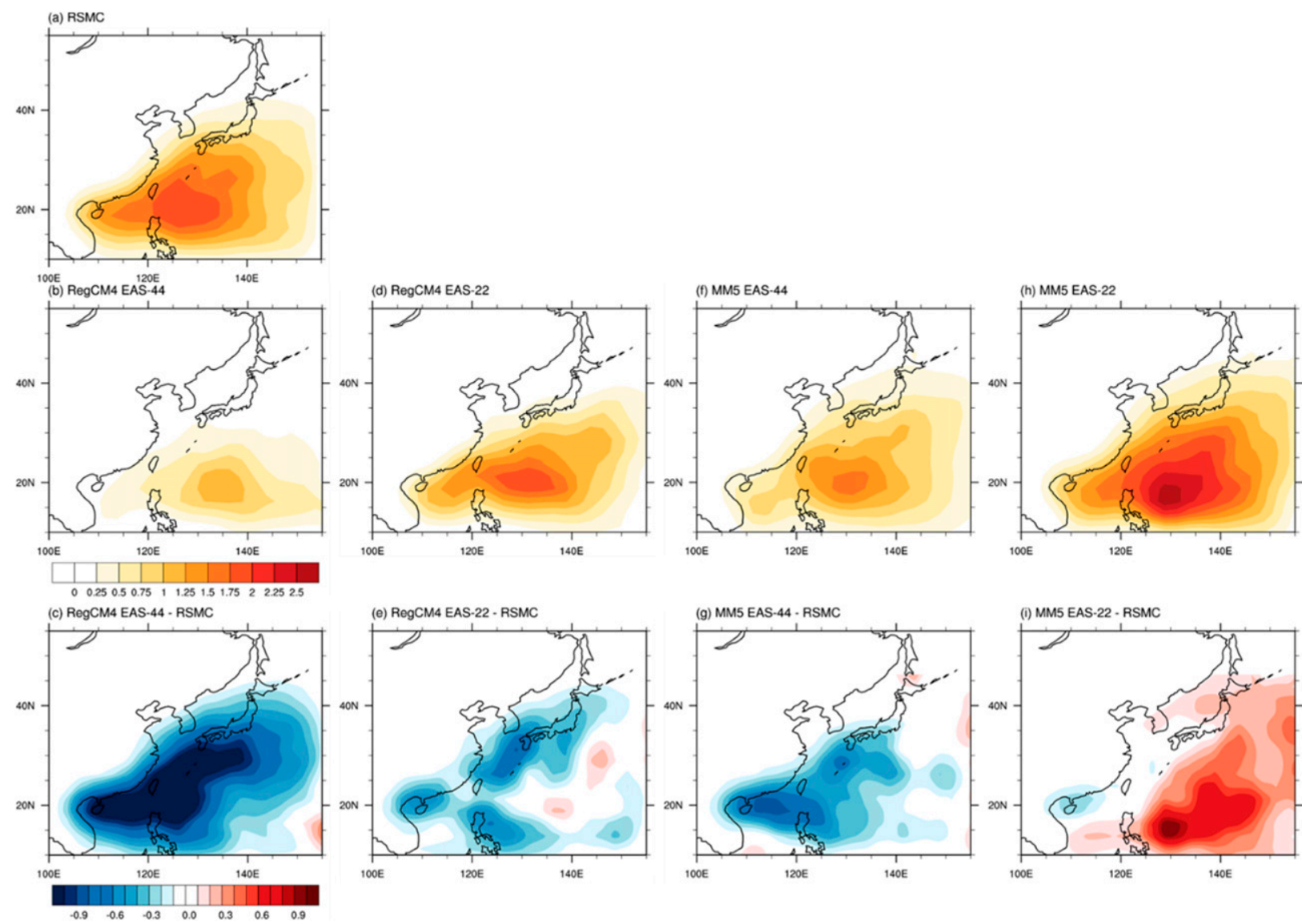

FIG. 3. Climatological mean of TC track density in the (a) RSMC, (b),(d) RegCM4, and (f),(h) MM5, and (c),(e),(g),(i) difference between RSMC and each model during 20 years (1989-2008).

simulated more TC genesis than the RegCM4_EAS44, and reasonably captured the core location of TC genesis over the PS despite slight underestimation of TC genesis. Similar to the RegCM4, the MM5 considerably increased TC genesis as the horizontal resolution became higher. However, TC genesis over the PS was significantly overestimated in the MM5_EAS22.

RCMs with good performance for TC tracks over the WNP, particularly coastal regions, can be advantageous for the estimation of TC damage in East Asia. Therefore, we analyzed the climatological mean of TC track density in all experiments, as shown in Fig. 3. The core location of the TC track density was located in the sea northeast of the Philippines in the best track data. In addition, TCs made landfall in a variety of East Asian countries and regions, including the Korean Peninsula, Japan, China, Taiwan, the Philippines, and Vietnam. In the RegCM4_ EAS44, TC track density near East Asian coastal regions was significantly underestimated, and TC landfall in East Asia was scarcely captured. As with the TC genesis density, the bias of TC track density notably decreased as the horizontal resolution increased in the RegCM4_EAS22. Therefore, the RegCM4 could improve the performance for TC track density in most analysis areas when the horizontal resolution was increased. The MM5_EAS44 improved TC track density compared with the RegCM4_EAS44, although the density over the core region was still underestimated. In particular, the northward migration of TC tracks was realistically simulated in the MM5_EAS44. However, it still underestimated the TC track density over the coastal regions around the SCS. In the MM5_ EAS22, the spatial distribution of track density was similar to that of the best track data, but tended to be overestimated between the PS and the eastern part of the domain $\left(10^{\circ}-30^{\circ} \mathrm{N}\right.$, $\left.125^{\circ}-155^{\circ} \mathrm{E}\right)$. The MM5_EAS22 notably improved the TC track density around coastal regions associated with TC landfall in the East Asian countries. Therefore, in both RCMs, the higher horizontal resolution led to more accurate simulation of TC track density near the coastal regions of East Asia, indicating added value. This added value associated with the higher model resolution resulted in increased TC genesis, as shown in Fig. 2, as well as longer TC life cycles because of enhanced TC intensities.

Very high resolution $(1-4 \mathrm{~km})$ is required to directly resolve TC core dynamics, which is directly associated with simulated TC intensity (Chen et al. 2007; Davis et al. 2010). This implies that the TC activities simulated by RCMs are significantly affected by the convection scheme, because $50-$ and $25-\mathrm{km}$ horizontal resolutions are not high enough for the direct simulation of strong convective activity in the TC core region. Therefore, we analyzed convective precipitation directly simulated by 
(a) RegCM4 EAS-44

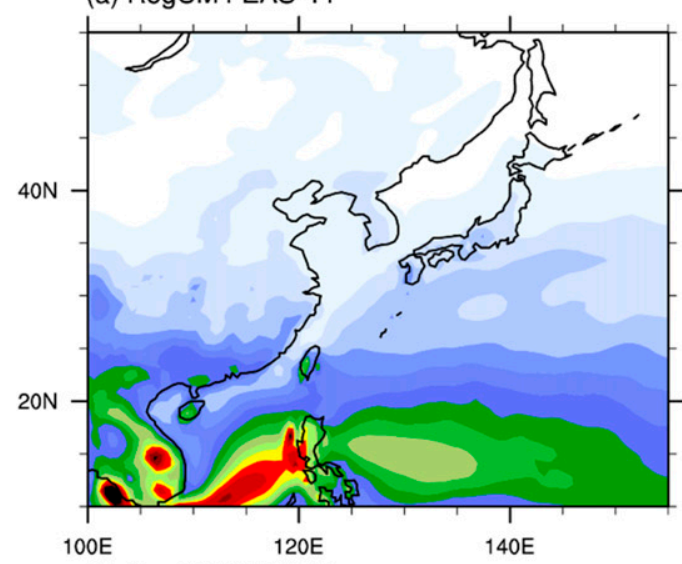

(b) RegCM4 EAS-22

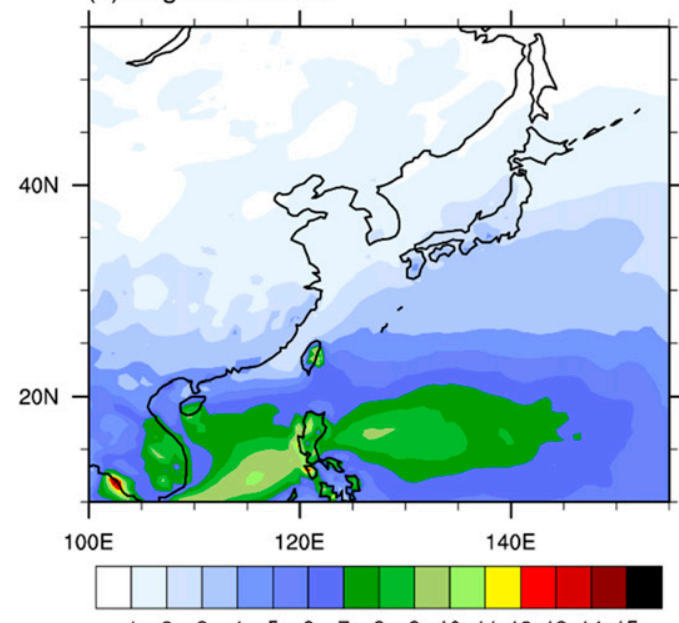

(c) RegCM4 (EAS-22 - EAS-44)

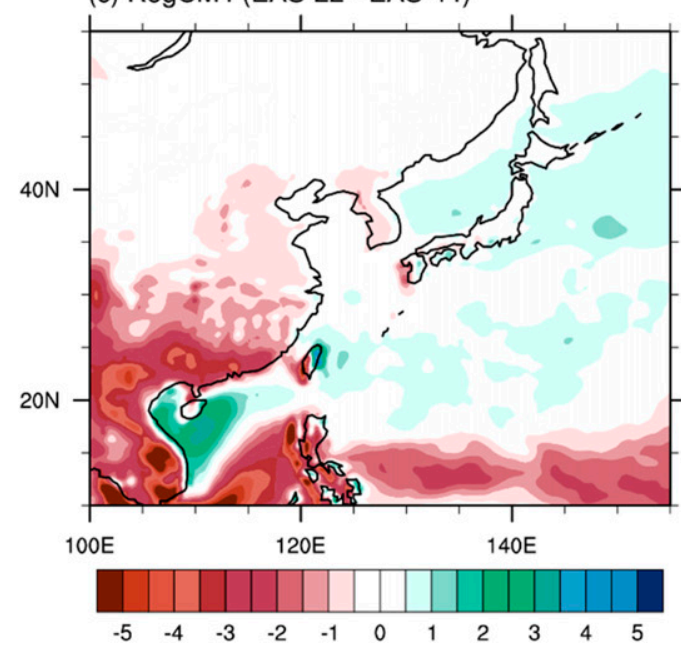

(d) MM5 EAS-44

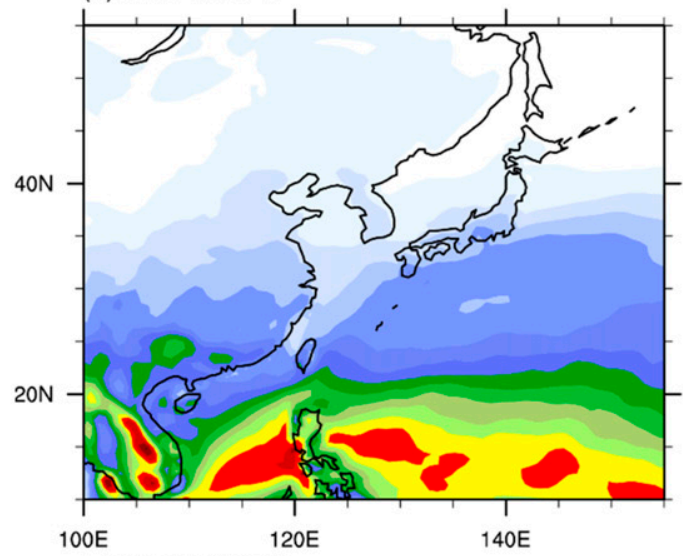

(e) MM5 EAS-22

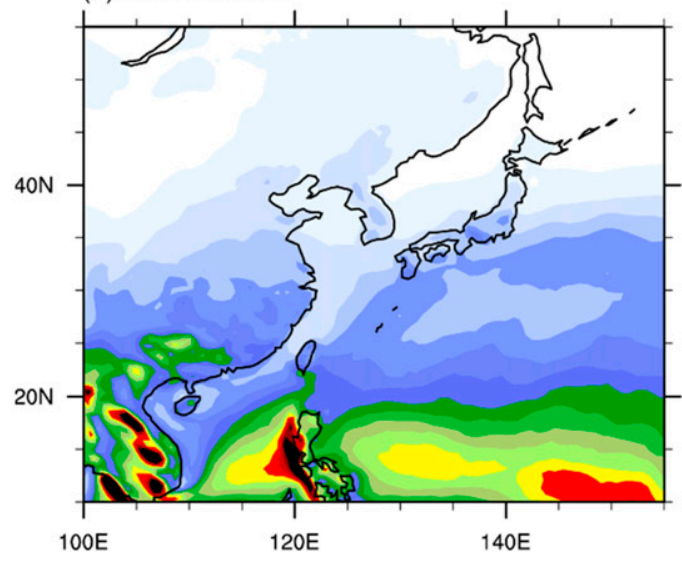

(f) MM5 (EAS-22 - EAS-44)

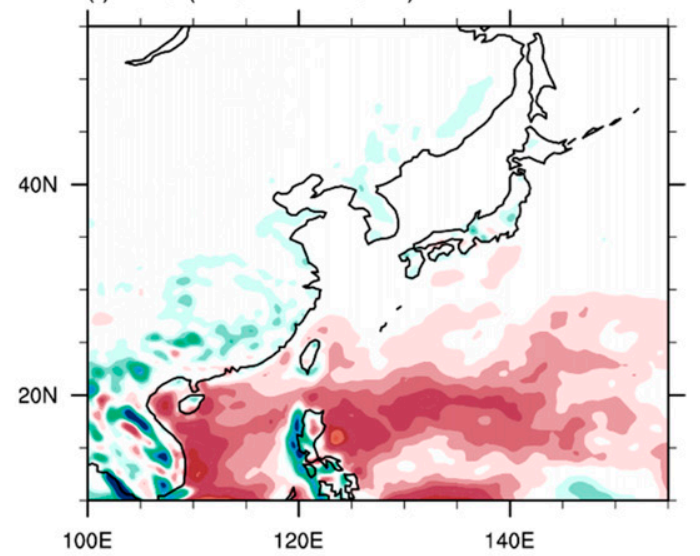

FIG. 4. Climatological mean of convective precipitation $\left(\mathrm{mm} \mathrm{day}^{-1}\right)$ in (a),(b) RegCM4 and (d),(e) MM5, and (c),(f) differences between EAS22 and EAS44 during 20 years (1989-2008).

convection schemes to determine the reason for the different TC simulations between the EAS44 and EAS22 experiments. Figure 4 shows the 20 -yr mean convective precipitation and its difference between the 25 - and 50-km horizontal resolutions.
All experiments consistently showed that most convective precipitation occurred around the equator and decreased with increased latitude. However, the RegCM4 had less convective precipitation and narrower core areas compared with the 


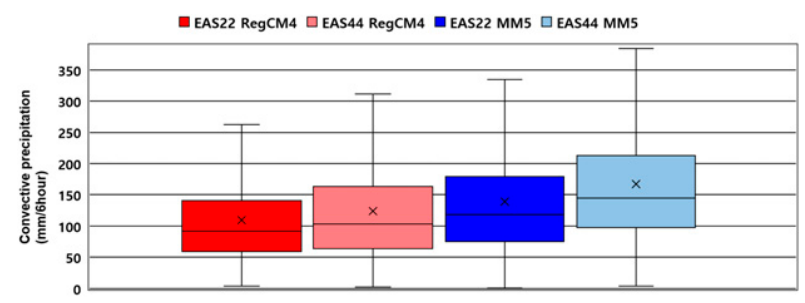

FIG. 5. Boxplot of the area-summed non-TC convective precipitation within $10^{\circ}-20^{\circ} \mathrm{N}, 125^{\circ}-145^{\circ} \mathrm{E}$ in each model during 20 years (1989-2008).

MM5. Both models tended to simulate more convective precipitation near the core regions of TC genesis (i.e., PS and SCS) at the lower horizontal resolution. Similar results, with a decrement of convective precipitation with increased horizontal resolution, were shown in previous studies (Boyle and Klein 2010; Duffy et al. 2003; Li et al. 2011). This trend may occur because with increased horizontal resolution, the role of cumulus parameterization stabilizing the atmosphere decreases and relevant convective precipitation is reduced as the role of cloud microphysics increases. Less convective precipitation around the core regions of TC genesis in the higher-resolution

(a) NTC $\left[\mathrm{yr}^{-1}\right]$

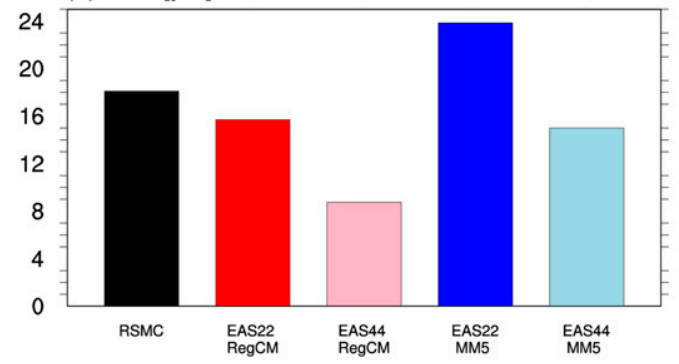

(b) Duration $\left[10^{2}\right.$ hour $\left.\mathrm{yr}^{-1}\right]$

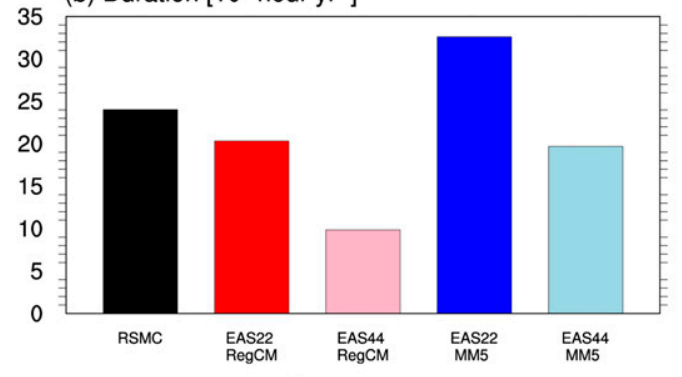

(c) Mean MWS $\left[\mathrm{m} \mathrm{s}^{-1}\right]$

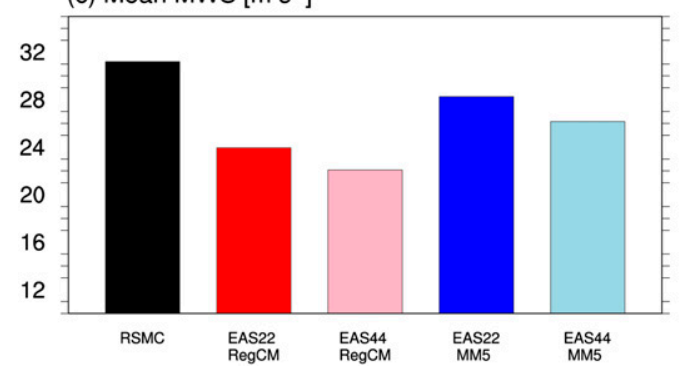

experiments indicates the reduced role of the convection scheme (Figs. 4c,f). In addition, we analyzed convective precipitation caused by non-TCs (Fig. 5). The non-TC convective precipitation was calculated when there was no TC center in the analysis area. The analysis area was defined as $10^{\circ}-20^{\circ} \mathrm{N}$, $125^{\circ}-145^{\circ} \mathrm{E}$, where TCs mainly occurred. The most crucial point is that non-TC convective precipitation was more in EAS44 than EAS22 for both models. Therefore, RCMs with the higher resolution simulated more TC genesis than those with the lower resolution because increased horizontal resolution led to the reduction of atmospheric stabilization by convection schemes (Ma and Tan 2009). In contrast, the RCMs with $50-\mathrm{km}$ resolution tended to exaggerate the stabilization by convection schemes around the core regions of TC genesis, which resulted in the genesis of fewer TCs.

We also analyzed the quantitative characteristics of TCs related to frequency, life cycle, and intensity in all experiments (Fig. 6). The number of tropical cyclones (NTC) indicates the annual mean frequency of TC genesis. Although the RegCM4_ EAS44, as well as the RegCM4_EAS22, simulated lower NTCs compared with the best track data, the NTC results were improved when the horizontal resolution was increased. The MM5 with 25 (50)-km horizontal resolution simulated more

(d) PDI $\left[10^{10} \mathrm{~m}^{3} \mathrm{~s}^{-2} \mathrm{yr}^{-1}\right]$

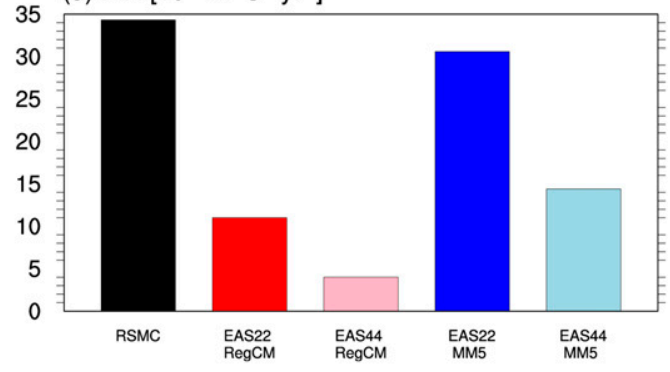

(e) Mean LMI [ $\left.\mathrm{m} \mathrm{s}^{-1}\right]$

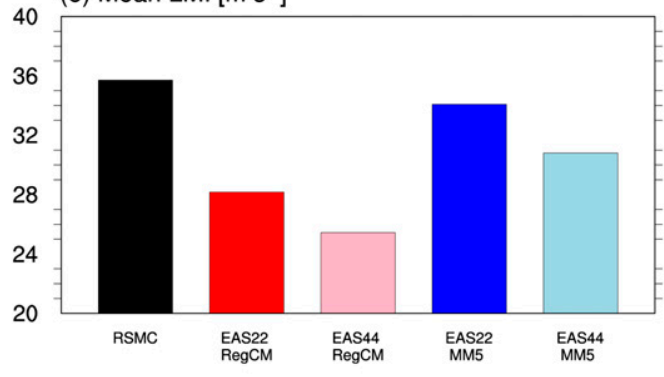

FIG. 6. The 20-yr mean (a) NTC, (b) duration, (c) mean MWS, (d) PDI, and (e) mean LMI in the RSMC best track data and models. 
(a) MWS

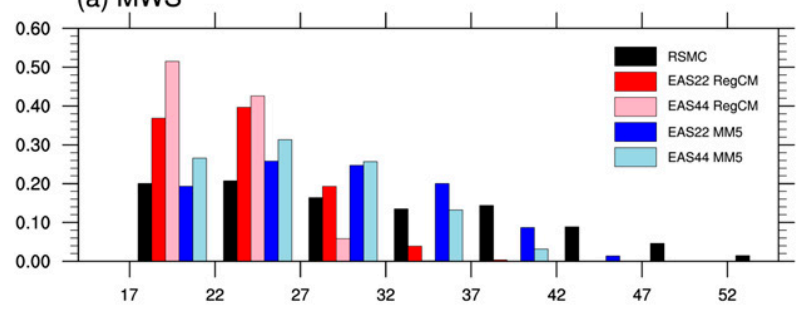

(b) SLP

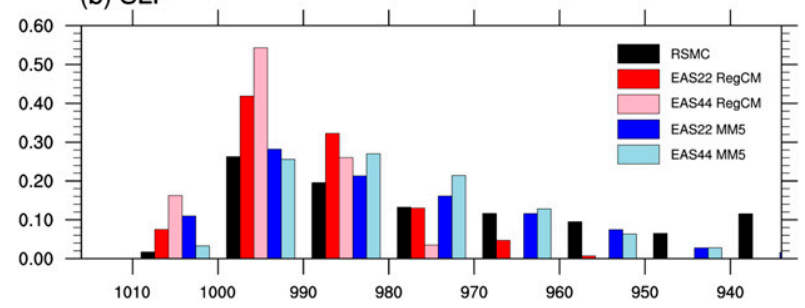

FIG. 7. Distribution of (a) maximum wind speed $\left(\mathrm{m} \mathrm{s}^{-1}\right)$ and (b) minimum sea level pressure ( $\mathrm{hPa}$ ) in the RSMC best track data and models during 20 years (1989-2008).

(less) TC genesis compared with the best track data. Simulated TC duration was quite similar to the simulated NTC, but mean maximum wind speed (MWS) was underestimated in all experiments because 50 - and $25-\mathrm{km}$ horizontal resolutions were insufficient to reproduce intense TCs. The MM5_EAS22 had the smallest error, and the higher horizontal resolution led to the better performance of mean MWS. The PDI is a comprehensive index that is influenced by the frequency, duration, and intensity of TCs. The MM5_EAS22 simulated higher NTCs and longer durations compared with the best track data, but the PDI was slightly underestimated because of weakened mean MWS. The PDI values of the other models (RegCM4_EAS22, RegCM4_EAS44, and MM5_EAS44) were notably small compared with that of the best track data because all the factors (frequency, duration, and intensity) were underestimated. LMI also showed better performance with the higher-resolution models. In summary, the modeling of the frequency and duration of TCs could be improved by the RegCM4 with higher resolution, whereas those tended to be overestimated (underestimated) by the MM5 with higher (lower) resolution. However, both models more realistically simulated MWS, PDI, and LMI in relation to TC intensity with increased horizontal resolution.

Probability density functions (PDFs) of the MWS and minimum sea level pressure for all experiments are presented in Fig. 7. In the best track data, the PDFs of MWS and minimum sea level pressure were evenly distributed between weak TCs and intense TCs. However, the PDFs of both models were skewed toward weak TCs, especially in the RegCM4_EAS44, which could not simulate strong TCs above $32 \mathrm{~m} \mathrm{~s}^{-1}$. Despite the slight improvement of TC intensity simulation, it was still difficult for the RegCM4_EAS22 to simulate powerful TC intensities above $37 \mathrm{~m} \mathrm{~s}^{-1}$. The MM5 more reasonably reproduced the PDF of MWS for strong TCs compared with the RegCM4. In particular, the MM5_EAS22 was the only experiment to simulate strong TCs with intensities exceeding $42 \mathrm{~m} \mathrm{~s}^{-1}$. The PDF of minimum sea level pressure was not considerably different from that of MWS. In both RegCM4 experiments, more than $80 \%$ of PDF distributions were concentrated above $980 \mathrm{hPa}$. In contrast, the MM5 produced a PDF distribution of sea level pressure comparable with that of the best track data.

\section{b. Impact on landfalling TCs}

It is significantly important for coastal East Asian countries to accurately predict TC characteristics such as track, intensity, and precipitation when TCs make landfall, as these characteristics are directly related to property damage and casualties. The characteristics of landfalling TCs and associated precipitation were evaluated to identify the impacts of the different horizontal resolutions. Figure 8 and Table 2 show the firstlandfall points and the number of landfall TCs in the best track data and four experiments. For clarification, we only analyzed the first landfalls of TCs; that is, the first time the center of each landfalling TC was located over an East Asian land region. During the 20 -yr period in the best track data 240 TCs made landfall in the East Asian countries. Only a small percentage of the landfalling TCs migrated northward to the midlatitudes (i.e., the Korean Peninsula and Japan) in the RegCM4_EAS44 compared with observation and other models. This was associated with the underestimation of TC intensity (Fig. 7), which could lead to easier decay of TCs around the midlatitudes. The RegCM4_EAS44 excessively underestimated the number of landfalling TCs because TC genesis was also underestimated and shifted eastward far from the land (Fig. 2b). In the RegCM4_EAS22, the number of landfalling TCs significantly increased by a factor of about 3 . However, the model still underestimated the number of TCs landfalling in the midlatitudes such as in the Korean Peninsula and Japan. Compared with the RegCM4, the MM5 realistically simulated many more TC landfalls. In particular, the MM5_EAS22 showed the best performance in terms of landfalling TCs, with results comparable with the best track data. Consequently, both of the RCMs could improve the simulation of landfalling TCs in East Asian countries with increased horizontal resolution.

To prepare for intense TCs, it is essential to accurately forecast how many TCs will make landfall and how strong they will be. Therefore, we analyzed the characteristics (i.e., frequency and intensity) of TCs at first landfall in East Asia in the best track data and models (Fig. 9). The MM5_EAS22 showed the best performance in terms of the number of landfalling TCs; it properly reproduced 235 landfalling TCs in the $20-\mathrm{yr}$ period. The RegCM4_EAS22 and MM5_EAS44 underestimated the number of landfalling TCs by about $60 \%$ compared with the best track data. The RegCM4_EAS44 hardly reproduced landfalling TCs because of underestimated TC genesis and the eastward shifted core location of TC genesis (Fig. 2b). In both models, the numbers of landfalling TCs were prominently improved with the finer horizontal resolution. The TC intensities (i.e., minimum sea level pressure and MWS) simulated by the RegCM4 were still quite weak, but were slightly improved when the horizontal resolution was increased. The MM5 reproduced the minimum sea level pressures of landfalling TCs more realistically compared with the RegCM4, and the difference between the two MM5 
(a) RSMC

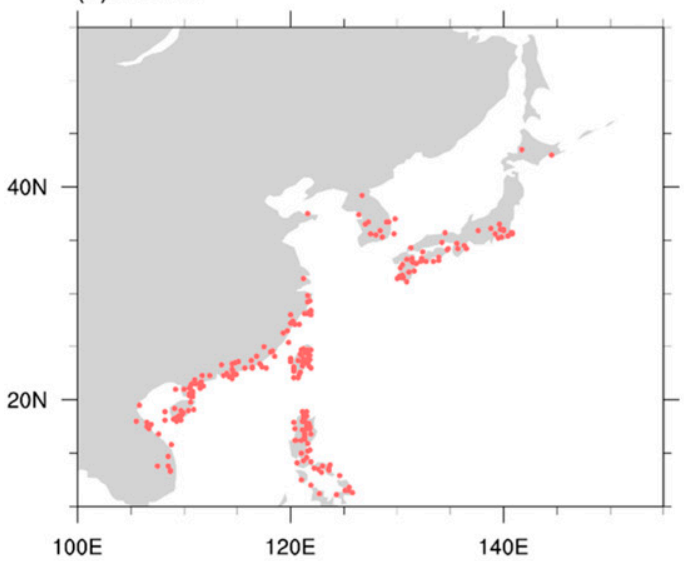

(b) RegCM4 EAS-44

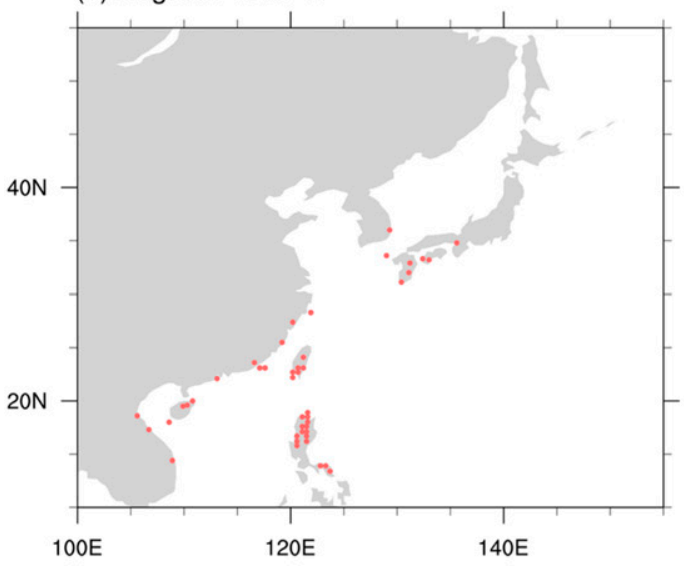

(d) MM5 EAS-44

(c) RegCM4 EAS-22
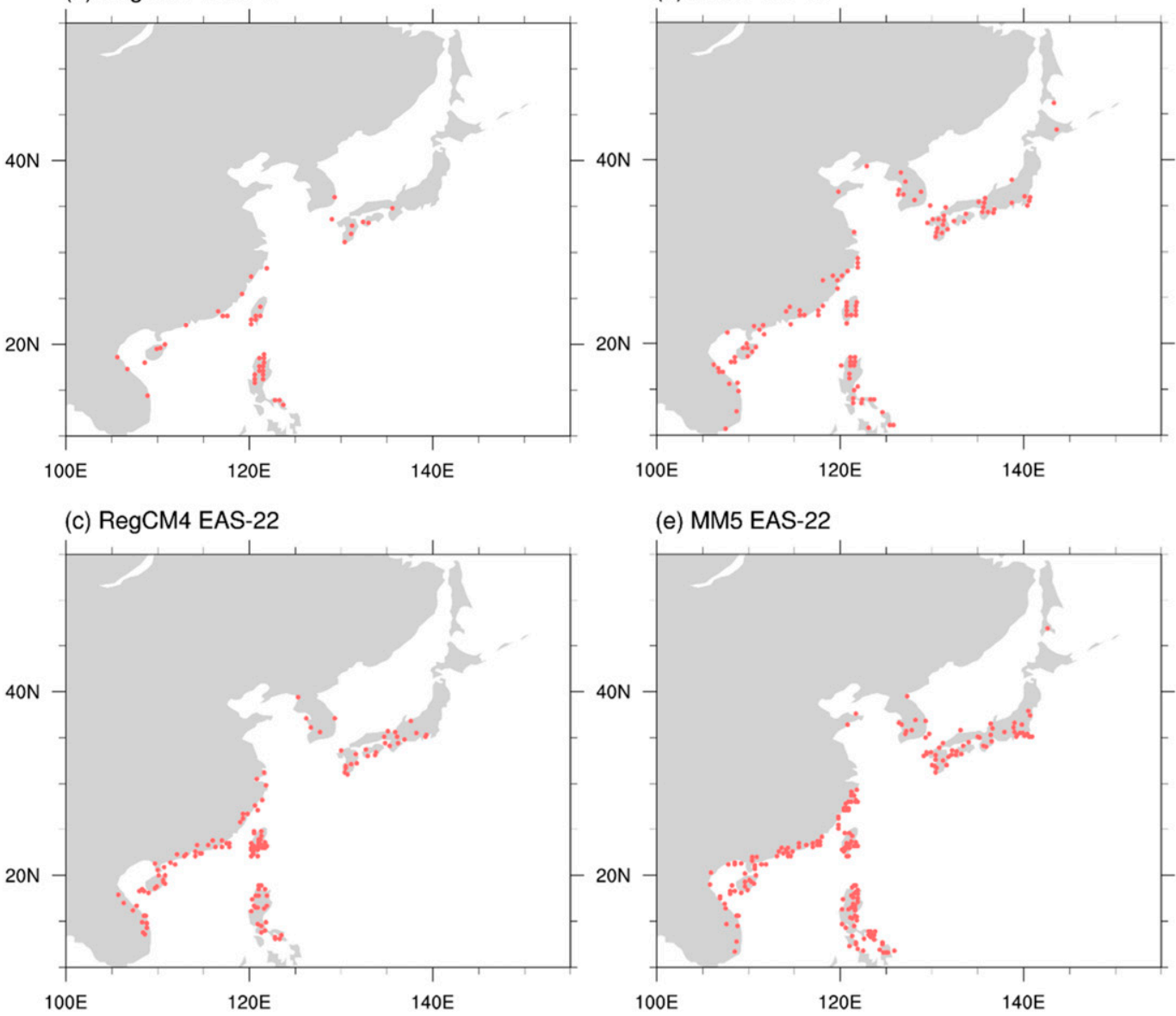

(e) MM5 EAS-22

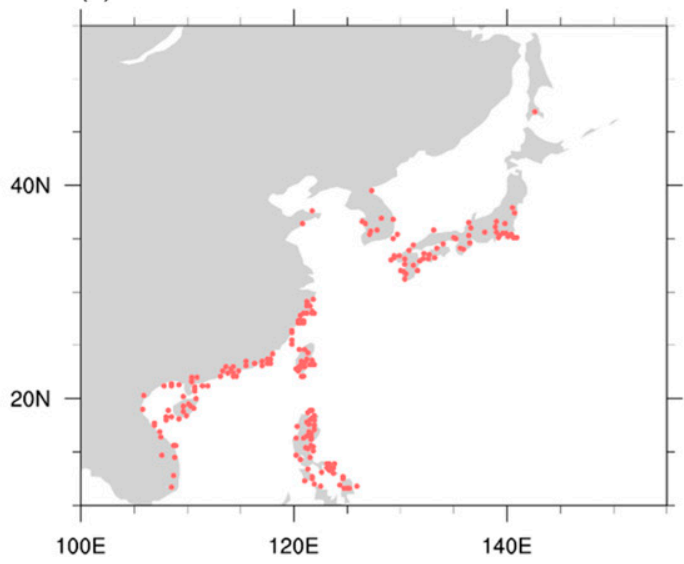

FIG. 8. First-landfall points of TCs in the RSMC best track data and models during 20 years (1989-2008).

experiments was quite small. However, MWS became more similar to the best track data when the horizontal resolution was increased. In summary, it was apparent that the frequency and intensity of TCs landfalling in East Asia were better simulated by the MM5 than the RegCM4, and that increased model resolution led to improved simulation of these characteristics.
TC-induced precipitation causes substantial casualties and damage in East Asian countries. According to Park et al. (2015), rainfall is a more important factor in TC damage than wind over South Korea. For example, heavy precipitation induced by Typhoons Rusa in 2002, Morakot in 2009, and Jebi in 2018 resulted in significant damage in South Korea, Taiwan, and Japan, respectively (Chien and Kuo 2011; Lee 
TABLE 2. The number of landfall TCs in the RSMC and models during 20 years (1989-2008) in each region.

\begin{tabular}{lccccrr}
\hline \hline & Korea & Japan & China & Taiwan & Southeast Asia & Philippines \\
\hline RSMC & 12 & 48 & 86 & 33 & 6 & 13 \\
RegCM4 EAS-44 & 1 & 7 & 14 & 30 & 4 & 13 \\
RegCM4 EAS-22 & 5 & 26 & 45 & 21 & 10 & 25 \\
MM5 EAS-44 & 9 & 35 & 43 & 24 & 16 & 26 \\
MM5 EAS-22 & 12 & 53 & 70 & & & 59 \\
\hline
\end{tabular}

and Choi 2010; Mori et al. 2019). Bakkensen et al. (2018) also highlighted the importance of rainfall when considering future TC damage. Therefore, reliable simulation of TCinduced precipitation is essential for numerical modeling. To evaluate model performance for TC-induced precipitation, we analyzed the total amounts of precipitation induced by the landfalling TCs in the best track data and models for a 20-yr period (Fig. 10). In the best track data, the coastal regions in Japan, China, Taiwan, the Philippines, Vietnam, and the Korean Peninsula were notably affected by TC-induced precipitation. In particular, the precipitation per unit area was highest in Taiwan and the Philippines. The RegCM4 EAS44 could not properly simulate TC-induced precipitation overall because it underestimated the frequencies of TC genesis and landfall (Figs. 2b and 8b). In the RegCM4_ EAS22, with the higher model resolution, TC-induced precipitation was relatively improved in the coastal regions, but it was still somewhat underestimated compared with observations. In particular, the RegCM4 models could not reproduce TC-induced precipitation over midlatitude areas such as Japan and the Korean Peninsula, as TC activity over these regions was significantly underestimated (Figs. 3b,c). In contrast, the MM5_EAS44 had results similar to observations to some extent, but TC-induced precipitation over the subtropics was overestimated in the case of the MM5_EAS22. As shown in Fig. 11, we calculated the total amounts of TCinduced precipitation over several East Asian countries and regions located in the coastal regions of the WNP (the Korean Peninsula, Japan, China, Taiwan, the Philippines, and Southeast Asia). The Southeast Asian countries included Vietnam, Cambodia, Laos, and Thailand, which were situated in the southwestern part of the analysis domain. The MM5 tended to simulate more TC-induced precipitation than the RegCM4 over most regions. In particular, the RegCM4_EAS44 significantly underestimated TC-induced precipitation over all regions compared with observations. In addition, both models with higher resolution consistently simulated more TC-induced precipitation than those with lower resolution, indicating improved simulation of TC-induced precipitation. This improvement can be attributed to the fact that increasing model resolution led to more reasonable characteristics (i.e., frequency and intensity) of TC landfalls in East Asia, as shown in Figs. 8 and 9. In particular, the increased TC-induced precipitation in the experiments with higher resolution may be more affected by the increased frequency of TC landfalls rather than enhanced intensity, because the sensitivity of frequency to horizontal (a) landfall NTC

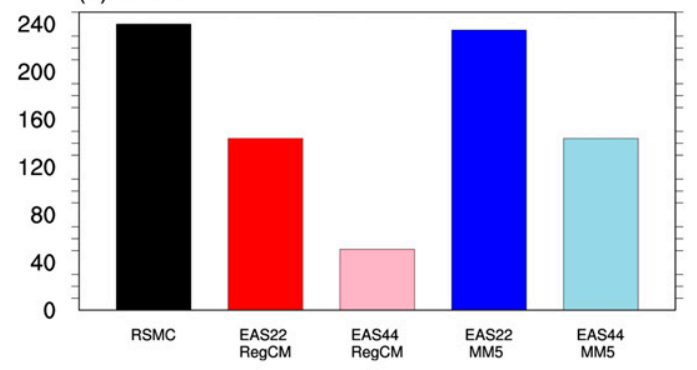

(b) landfall SLP $[\mathrm{hPa}]$

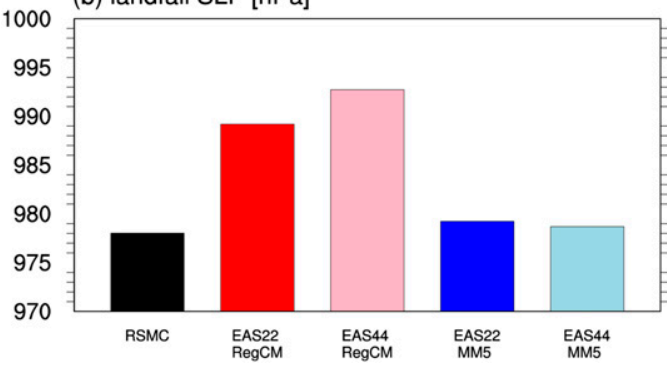

(c) landfall MWS $\left[\mathrm{m} \mathrm{s}^{-1}\right]$

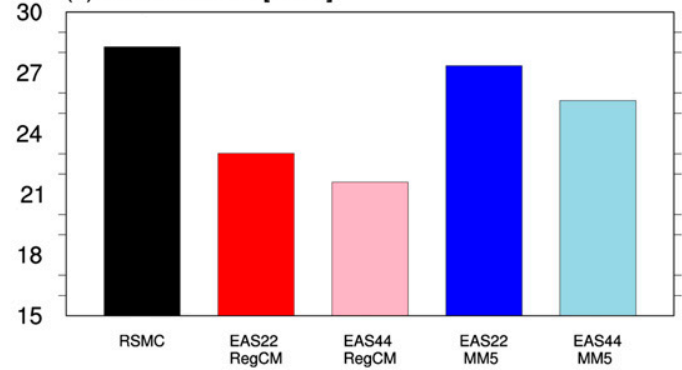

FIG. 9. (a) The number of landfall TCs, (b) mean sea level pressure, and (c) mean MWS at first landfall in the RSMC best track data and models during 20 years (1989-2008). 
(a) APHRODITE

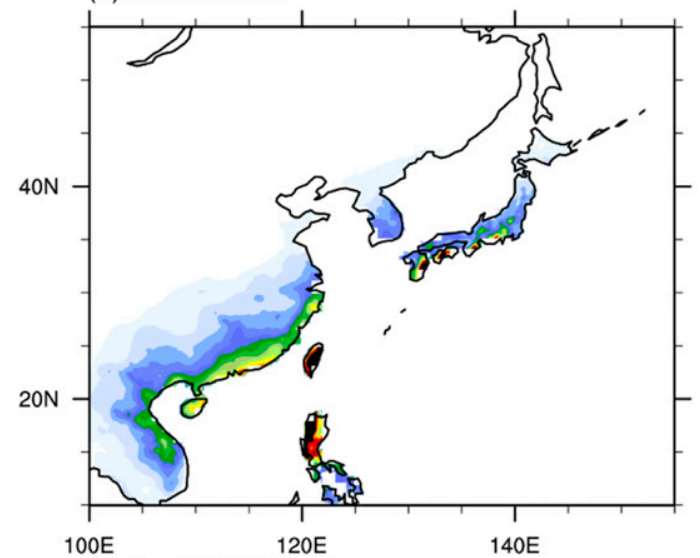

(b) RegCM4 EAS-44

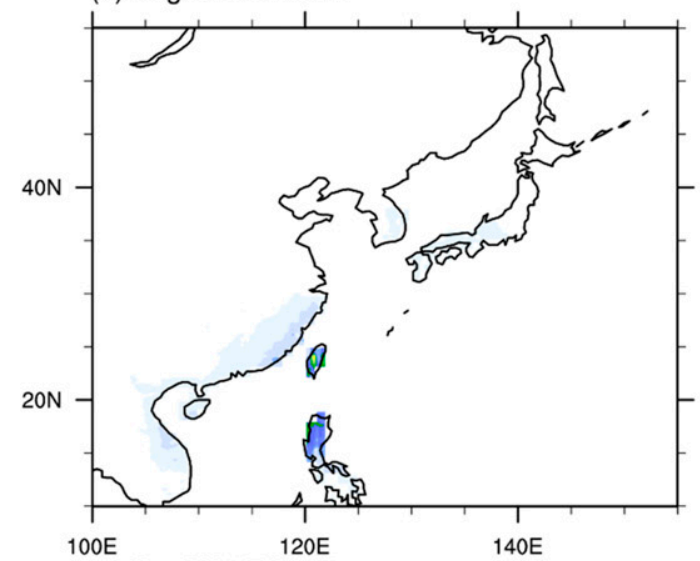

(d) MM5 EAS-44

(c) RegCM4 EAS-22
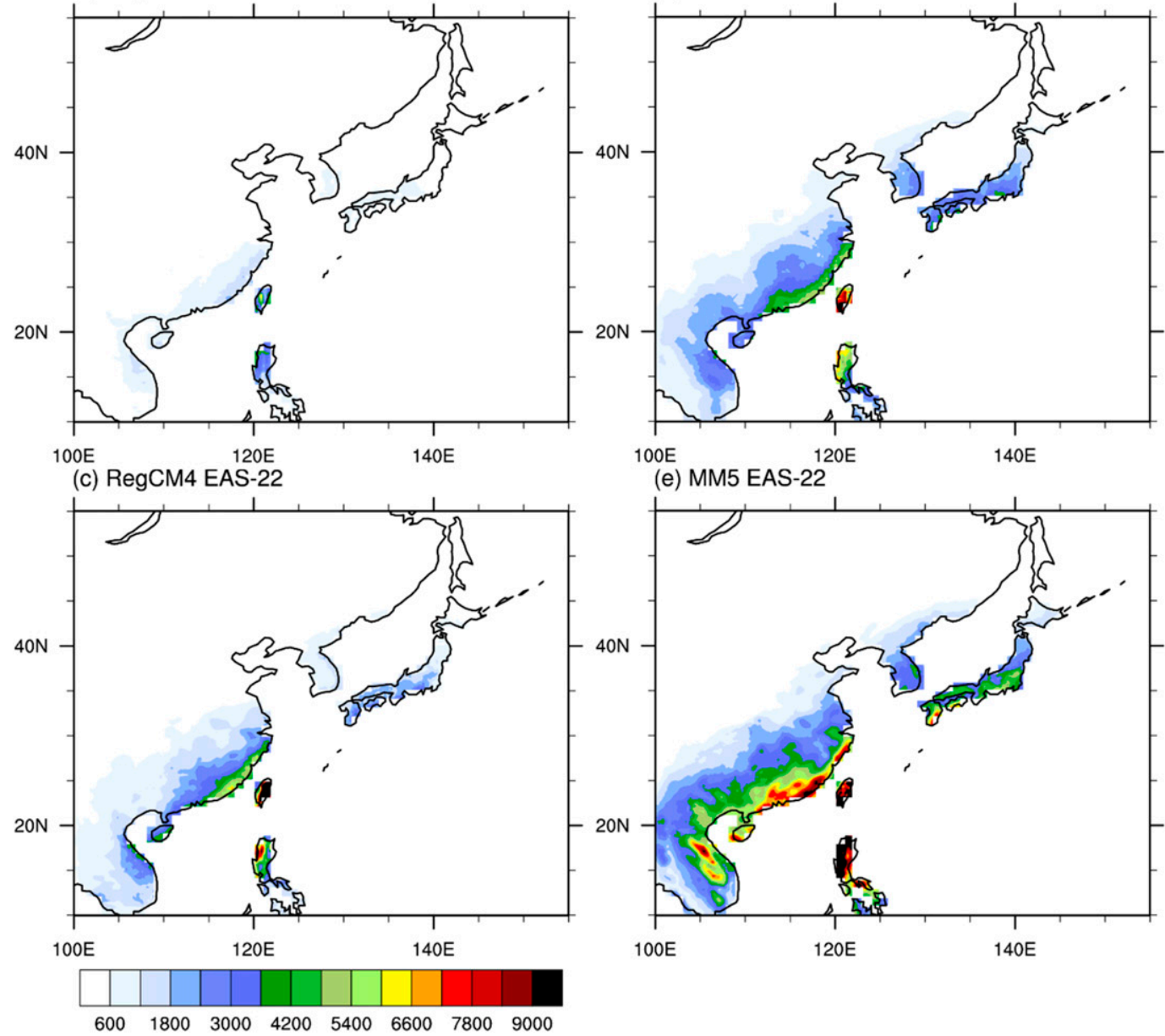

(e) MM5 EAS-22

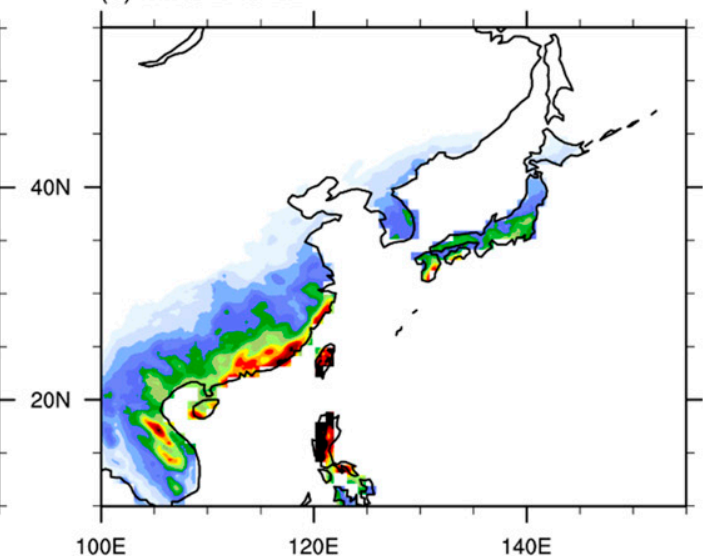

FIG. 10. TC-induced accumulated precipitation ( $\mathrm{mm})$ in the APHRODITE and models during 20 years (1989-2008).

resolution was prominently larger than that of TC intensity (see Fig. 9). Therefore, these results indicate that the finer horizontal resolution can lead to added value improving the simulation of TCs landfalling in East Asia in terms of the characteristics of the TCs and associated precipitation.

\section{Summary and conclusions}

In this study, two RCMs (RegCM4 and MM5) were evaluated to investigate the impact of different horizontal resolutions based on the CORDEX framework. Both models were 
(a) Korea $\left[10^{5} \mathrm{~mm}\right]$

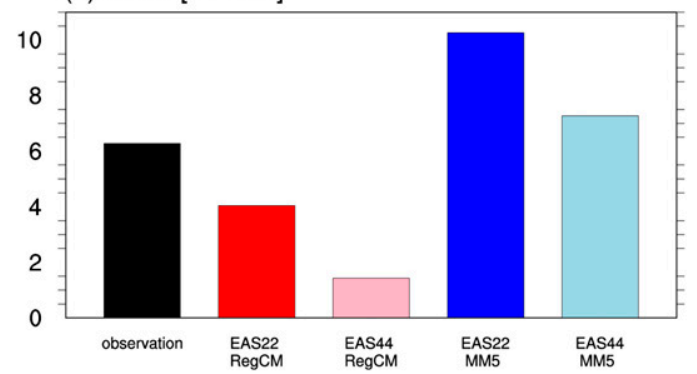

(b) Japan $\left[10^{5} \mathrm{~mm}\right]$

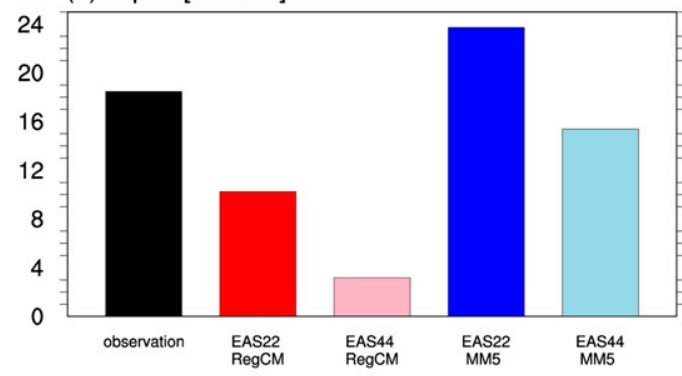

(c) China $\left[10^{6} \mathrm{~mm}\right]$

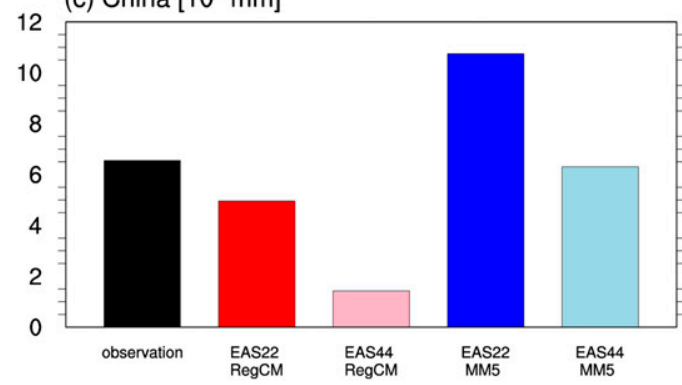

(d) Taiwan $\left[10^{5} \mathrm{~mm}\right]$

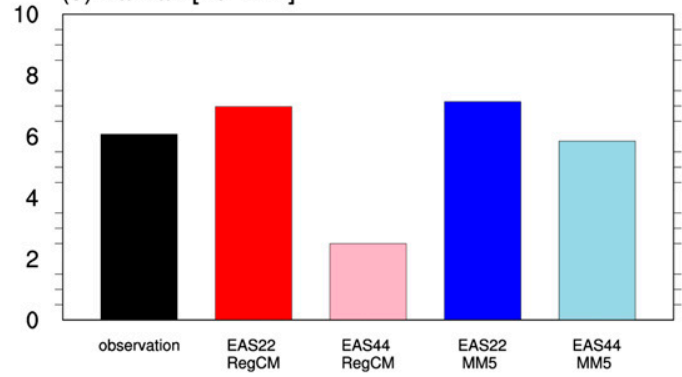

(e) Southeast Asia $\left[10^{5} \mathrm{~mm}\right]$

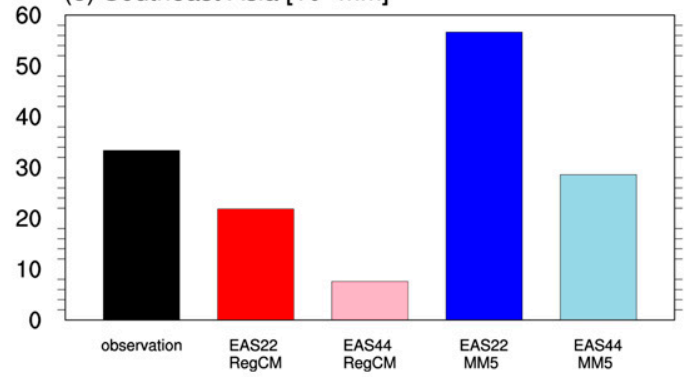

(f) Philippines $\left[10^{5} \mathrm{~mm}\right]$

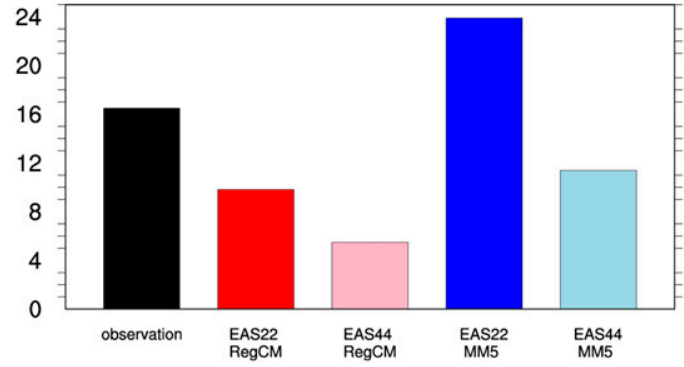

FIG. 11. TC-induced accumulated precipitation of the APHRODITE and models during 20 years (1989-2008) in the subregions: (a) Korean Peninsula $\left(34^{\circ}-42^{\circ} \mathrm{N}, 124^{\circ}-130^{\circ} \mathrm{E}\right)$, (b) Japan $\left(30^{\circ}-46^{\circ} \mathrm{N}, 124^{\circ}-130^{\circ} \mathrm{E}\right.$; excluding overlap with the Korean Peninsula), (c) China (excluding the Korean Peninsula, Japan, Taiwan, the Philippines, and Southeast Asia), (d) Taiwan $\left(22^{\circ}-25.5^{\circ} \mathrm{N}, 119.5^{\circ}-122.5^{\circ} \mathrm{E}\right)$, (e) Southeast Asia $\left(10^{\circ}-17^{\circ} \mathrm{N}, 100^{\circ}-110^{\circ} \mathrm{E}\right.$ and $17^{\circ}-25^{\circ} \mathrm{N}$, $\left.100^{\circ}-108^{\circ} \mathrm{E}\right)$, and (f) the Philippines $\left(10^{\circ}-19^{\circ} \mathrm{N}, 119^{\circ}-126^{\circ} \mathrm{E}\right)$. Precipitation was only calculated over land.

conducted at horizontal resolutions of $25 \mathrm{~km}$ (EAS22) and $50 \mathrm{~km}$ (EAS44), and were driven by ERA-Interim. The configuration of each model was almost the same except for the horizontal resolution. In the 20-yr (1989-2008) climatological mean, finer horizontal resolution increased TC genesis and track densities. Therefore, both models showed improved simulation of TC tracks that could cause damage to the coastal countries in East Asia when the horizontal resolution was increased from 50 to $25 \mathrm{~km}$. Reduced convective precipitation could be one reason why TC genesis was increased at $25-\mathrm{km}$ horizontal resolution. More convective precipitation at $50-\mathrm{km}$ horizontal resolution could enhance atmospheric stabilization, which would be an unfavorable condition for TC development. The RegCM4 model with finer horizontal resolution could improve simulation of most characteristics of TCs, although this improvement was not significant. However, the MM5 with higher resolution prominently improved simulation of mean MWS, PDI, and mean LMI in relation to TC intensity, despite overestimation of frequency and duration.
The characteristics of landfalling TCs and TC-induced precipitation were evaluated to examine the influence of horizontal resolution. The number of TCs landfalling in East Asian countries was simulated more reasonably in the MM5 than in the RegCM4. Both models had better performance at the higher horizontal resolution because the simulated characteristics of the TCs were improved in the East Asian coastal areas. In the RegCM4_EAS44, TC-induced precipitation was extremely underestimated in most East Asian coastal regions, but it was improved with the increased horizontal resolution. TCinduced precipitation was somewhat underestimated (overestimated) at 50 (25)-km horizontal resolution in the MM5. The frequency and intensity of TCs landfalling in East Asian countries were more reasonably reproduced in the MM5 than in the RegCM4, and finer horizontal resolution led to better performance. In conclusion, simulation of all characteristics of TCs showed improved performance at the higher resolution $(25 \mathrm{~km})$ in the RegCM4. The MM5 with $25-\mathrm{km}$ horizontal resolution realistically simulated TC tracks around East Asian 
coastal regions, intensity, and the number of landfalling TCs, although the number of TCs generated, TC duration, and TCinduced precipitation were somewhat overestimated.

Through the evaluation experiments, this study showed that the simulation of TCs over the WNP varied depending on the model type and the horizontal resolution, although there were limitations in that only two RCMs and a single large-scale forcing dataset were used. Therefore, the results of this evaluation can be used to produce more reliable information on future changes in TCs. For example, it is possible to generate a performance-based ensemble averaging TCs over the WNP, as indicated by Suh et al. (2012) and Jin et al. (2016). In addition, it was clarified that increasing horizontal resolution in the CORDEX II framework led to added value in improving the simulation of general TC activity over the WNP, as well as the characteristics of landfalling TCs in coastal regions. These results imply that dynamical downscaling with high-resolution RCMs has an advantage for assessment studies of the impact of climate change on future change in TCs over the WNP.

Although Lee et al. (2019a) already analyzed future changes in TCs over the WNP using the results of the CORDEX-East Asia phase I, that study was not sufficient to resolve TC intensities and tracks around the East Asian coastal regions. Therefore, to provide more reliable information on future changes in TC activity over the WNP, we plan to investigate such future changes using the results of CORDEX-East Asia phase II with $25-\mathrm{km}$ horizontal resolution based on two climate change scenarios under representative concentration pathways (RCPs) 2.6 and 8.5.

Acknowledgments. This work was funded by the Korea Meteorological Administration Research and Development Program under Grant KMI (KMI2018-01211), and "Research and Development for KMA Weather, and Earth system Services-Development and Assessment of AR6 Climate Change Scenarios" under Grant KMA2018-00321.

\section{REFERENCES}

Bacmeister, J. T., K. A. Reed, C. Hannay, P. Lawrence, S. Bates, J. E. Truesdale, N. Rosenbloom, M. Levy, 2018: Projected changes in tropical cyclone activity under future warming scenarios using a high-resolution climate model. Climatic Change, 146, 547-560, https://doi.org/10.1007/S10584-016-1750-X.

Bakkensen, L. A., D.-S. R. Park, and R. S. R. Sarkar, 2018: Climate costs of tropical cyclone losses also depend on rain. Environ. Res. Lett., 13, 074034, https://doi.org/10.1088/17489326/aad056.

Barcikowska, M., F. Feser, W. Zhang, and W. Mei, 2017: Changes in intense tropical cyclone activity for the western North Pacific during the last decades derived from a regional climate model simulation. Climate Dyn., 49, 2931-2949, https://doi.org/ 10.1007/S00382-016-3420-0.

Bengtsson, L., H. Böttger, and M. Kanamitsu, 1982: Simulation of hurricane-type vortices in a general circulation model. Tellus, 34, 440-457, https://doi.org/10.3402/tellusa.v34i5.10830.

Bhaskar Rao, D., D. Hari Prasad, and D. Srinivas, 2009: Impact of horizontal resolution and the advantages of the nested domains approach in the prediction of tropical cyclone intensification and movement. J. Geophys. Res., 114, D11106, https:// doi.org/10.1029/2008JD011623.
Boyle, J., and S. A. Klein, 2010: Impact of horizontal resolution on climate model forecasts of tropical precipitation and diabatic heating for the TWP-ICE period. J. Geophys. Res., 115, D23113, https://doi.org/10.1029/2010JD014262.

Bozkurt, D., M. Rojas, J. P. Boisier, R. Rondanelli, R. Garreaud, and L. Gallardo, 2019: Dynamical downscaling over the complex terrain of southwest South America: Present climate conditions and added value analysis. Climate Dyn., 53, 67456767, https://doi.org/10.1007/S00382-019-04959-Y.

Camargo, S. J., 2013: Global and regional aspects of tropical cyclone activity in the CMIP5 models. J. Climate, 26, 9880-9902, https://doi.org/10.1175/JCLI-D-12-00549.1.

-, H. Li, and L. Sun, 2007: Feasibility study for downscaling seasonal tropical cyclone activity using the NCEP regional spectral model. Int. J. Climatol., 27, 311-325, https://doi.org/ 10.1002/joc. 1400 .

Cha, D.-H., C.-S. Jin, D.-K. Lee, and Y.-H. Kuo, 2011: Impact of intermittent spectral nudging on regional climate simulation using Weather Research and Forecasting model. J. Geophys. Res., 116, D10103, https://doi.org/10.1029/2010JD015069.

,-- , J.-H. Moon, and D.-K. Lee, 2016: Improvement of regional climate simulation of East Asian summer monsoon by coupled air-sea interaction and large-scale nudging. Int. J. Climatol., 36, 334-345, https://doi.org/10.1002/JOC.4349.

Chen, S. S., J. F. Price, W. Zhao, M. A. Donelan, and E. J. Walsh, 2007: The CBLAST-Hurricane program and the next-generation fully coupled atmosphere-wave-ocean models for hurricane research and prediction. Bull. Amer. Meteor. Soc., 88, 311-318, https://doi.org/10.1175/BAMS-88-3-311.

Chien, F.-C., and H.-C. Kuo, 2011: On the extreme rainfall of Typhoon Morakot (2009). J. Geophys. Res., 116, D05104, https://doi.org/10.1029/2010JD015092.

Choi, Y.-W., and J.-B. Ahn, 2017: Impact of cumulus parameterization schemes on the regional climate simulation for the domain of CORDEX-East Asia phase 2 using WRF model. Atmosphere, 27, 105-118, https://doi.org/10.14191/ATMOS.2017.27.1.105.

Christensen, J. H., T. R. Carter, M. Rummukainen, and G. Amanatidis, 2007: Evaluating the performance and utility of regional climate models: The PRUDENCE project. Climatic Change, 81, 1-6, https://doi.org/10.1007/s10584-006-9211-6.

Davis, C., W. Wang, J. Dudhia, and R. Torn, 2010: Does increased horizontal resolution improve hurricane wind forecasts? Wea. Forecasting, 25, 1826-1841, https://doi.org/10.1175/2010 WAF2222423.1.

Dee, D. P., and Coauthors, 2011: The ERA-Interim reanalysis: Configuration and performance of the data assimilation system. Quart. J. Roy. Meteor. Soc., 137, 553-597, https://doi.org/ 10.1002/qj.828.

Di Luca, A., R. de Elía, and R. Laprise, 2012: Potential for added value in precipitation simulated by high-resolution nested regional climate models and observations. Climate Dyn., 38, 1229-1247, https://doi.org/10.1007/S00382-011-1068-3.

Duffy, P., B. Govindasamy, J. P. Iorio, J. Milovich, K. R. Sperber, K. E. Taylor, M. F. Wehner, S. L. Thompson, 2003: High-resolution simulations of global climate, part 1: Present climate. Climate Dyn., 21, 371-390, https://doi.org/10.1007/S00382-003-0339-Z.

Emanuel, K. A., 1991: A scheme for representing cumulus convection in large-scale models. J. Atmos. Sci., 48, 2313-2329, https://doi.org/10.1175/1520-0469(1991)048<2313:ASFRCC $>2.0$. $\mathrm{CO} ; 2$.

2005: Increasing destructiveness of tropical cyclones over the past 30 years. Nature, 436, 686, https://doi.org/10.1038/ NATURE03906. 
_ 2013: Downscaling CMIP5 climate models shows increased tropical cyclone activity over the 21st century. Proc. Natl. Acad. Sci. USA, 110, 12 219-12 224, https://doi.org/10.1073/ PNAS.1301293110.

_- R. Sundararajan, and J. Williams, 2008: Hurricanes and global warming: Results from downscaling IPCC AR4 simulations. Bull. Amer. Meteor. Soc., 89, 347-368, https://doi.org/10.1175/BAMS89-3-347.

Frei, C., R. Schöll, S. Fukutome, J. Schmidli, and P. L. Vidale, 2006: Future change of precipitation extremes in Europe: Intercomparison of scenarios from regional climate models. J. Geophys. Res., 111, D06105, https://doi.org/10.1029/2005JD005965.

Fuentes-Franco, R., F. Giorgi, E. Coppola, and K. Zimmermann, 2017: Sensitivity of tropical cyclones to resolution, convection scheme and ocean flux parameterization over eastern tropical Pacific and tropical North Atlantic Oceans in the RegCM4 model. Climate Dyn., 49, 547-561, https://doi.org/10.1007/S00382-016-3357-3.

Giorgi, F., C. Jones, and G. R. Asrar, 2009: Addressing climate information needs at the regional level: The CORDEX framework. WMO Bull., 58, 175.

—_, and Coauthors, 2012: RegCM4: Model description and preliminary tests over multiple CORDEX domains. Climate Res., 52, 7-29, https://doi.org/10.3354/cr01018.

Gualdi, S., E. Scoccimarro, and A. Navarra, 2008: Changes in tropical cyclone activity due to global warming: Results from a high-resolution coupled general circulation model. J. Climate, 21, 5204-5228, https://doi.org/10.1175/2008JCLI1921.1.

Ho, C.-H., J.-H. Kim, H.-S. Kim, W. Choi, M.-H. Lee, H.-D. Yoo, T.-R. Kim, S. Park, 2013: Technical note on a track-patternbased model for predicting seasonal tropical cyclone activity over the western North Pacific. Adv. Atmos. Sci., 30, 12601274, https://doi.org/10.1007/S00376-013-2237-6.

Holtslag, A. A. M., E. I. F. De Bruijn, and H. Pan, 1990: A high resolution air mass transformation model for short-range weather forecasting. Mon. Wea. Rev., 118, 1561-1575, https://doi.org/ 10.1175/1520-0493(1990)118<1561:AHRAMT>2.0.CO;2.

Hong, S., Y. Noh, and J. Dudhia, 2006: A new vertical diffusion package with an explicit treatment of entrainment processes. Mon. Wea. Rev., 134, 2318-2341, https://doi.org/10.1175/MWR3199.1.

Huang, B., S. Polanski, and U. Cubasch, 2015: Assessment of precipitation climatology in an ensemble of CORDEX-East Asia regional climate simulations. Climate Res., 64, 141-158, https://doi.org/10.3354/CR01302.

Jin, C.-S., D.-H. Cha, D.-K. Lee, M.-S. Suh, S.-Y. Hong, H.-S. Kang, and C.-H. Ho, 2016: Evaluation of climatological tropical cyclone activity over the western North Pacific in the CORDEX-East Asia multi-RCM simulations. Climate Dyn., 47, 765-778, https://doi.org/10.1007/S00382-015-2869-6.

Jin, H., M. S. Peng, Y. Jin, and J. D. Doyle, 2014: An evaluation of the impact of horizontal resolution on tropical cyclone predictions using COAMPS-TC. Wea. Forecasting, 29, 252-270, https://doi.org/10.1175/WAF-D-13-00054.1.

Kain, J. S., 2004: The Kain-Fritsch convective parameterization: An update. J. Appl. Meteor., 43, 170-181, https://doi.org/ 10.1175/1520-0450(2004)043<0170:TKCPAU>2.0.CO;2.

Kanamitsu, M., and L. DeHaan, 2011: The added value index: A new metric to quantify the added value of regional models. J. Geophys. Res., 116, D11106, https://doi.org/10.1029/ 2011JD015597.

Kim, G., J. Kim, C.-J. Kim, C.-S. Jin, D.-H. Cha, M.-S. Suh, and S.-C. Park, 2014: Climate change projections over CORDEX East Asia domain using multi-RCMs. J. Climate Res., 9, 257268, https://doi.org/10.14383/CRI.2014.9.4.257.
Kim, H.-S., G. A. Vecchi, T. R. Knutson, W. G. Anderson, T. L. Delworth, A. Rosati, F. Zeng, M. Zhao, 2014: Tropical cyclone simulation and response to $\mathrm{CO}_{2}$ doubling in the GFDL CM2. 5 high-resolution coupled climate model. J. Climate, 27, 80348054, https://doi.org/10.1175/JCLI-D-13-00475.1.

Kim, J., and Coauthors, 2014: Evaluation of the CORDEX-Africa multi-RCM hindcast: Systematic model errors. Climate Dyn., 42, 1189-1202, https://doi.org/10.1007/S00382-013-1751-7.

Knutson, T. R., J. J. Sirutis, S. T. Garner, I. M. Held, and R. E. Tuleya, 2007: Simulation of the recent multidecadal increase of Atlantic hurricane activity using an 18-km-grid regional model. Bull. Amer. Meteor. Soc., 88, 1549-1565, https:// doi.org/10.1175/BAMS-88-10-1549.

Lee, D.-K., and S.-J. Choi, 2010: Observation and numerical prediction of torrential rainfall over Korea caused by Typhoon Rusa (2002). J. Geophys. Res., 115, D12105, https://doi.org/ 10.1029/2009JD012581.

_ D.-H. Cha, and H.-S. Kang, 2004: Regional climate simulation of the 1998 summer flood over East Asia. J. Meteor. Soc. Japan, 82, 1735-1753, https://doi.org/10.2151/jmsj.82.1735.

,-- , C.-S. Jin, and S.-J. Choi, 2013: A regional climate change simulation over East Asia. Asia-Pac. J. Atmos. Sci., 49, 655-664, https://doi.org/10.1007/S13143-013-0058-2.

Lee, H., and Coauthors, 2019: Future change in tropical cyclone activity over the western North Pacific in CORDEX-East Asia Multi-RCMs forced by HadGEM2-AO. J. Climate, 32, 50535067, https://doi.org/10.1175/JCLI-D-18-0575.1.

Lee, M., D. H. Cha, J. Moon, J. Park, C. S. Jin, and J. C. Chan, 2019: Long-term trends in tropical cyclone tracks around Korea and Japan in late summer and early fall. Atmos. Sci. Lett., 20, e939, https://doi.org/10.1002/asl.939.

Li, F., W. D. Collins, M. F. Wehner, D. L. Williamson, J. G. Olson, and C. Algieri, 2011: Impact of horizontal resolution on simulation of precipitation extremes in an aqua-planet version of Community Atmospheric Model (CAM3). Tellus, 63A, 884892, https://doi.org/10.1111/J.1600-0870.2011.00544.X.

Lucas-Picher, P., M. Wulff-Nielsen, J. H. Christensen, G. Aðalgeirsdóttir, R. Mottram, and S. B. Simonsen, 2012: Very high resolution regional climate model simulations over Greenland: Identifying added value. J. Geophys. Res., 117, D02108, https://doi.org/ 10.1029/2011JD016267.

Ma, L.-M., and Z.-M. Tan, 2009: Improving the behavior of the cumulus parameterization for tropical cyclone prediction: Convection trigger. Atmos. Res., 92, 190-211, https://doi.org/ 10.1016/J.ATMOSRES.2008.09.022.

Manabe, S., J. L. Holloway Jr., and H. M. Stone, 1970: Tropical circulation in a time-integration of a global model of the atmosphere. J. Atmos. Sci., 27, 580-613, https://doi.org/10.1175/ 1520-0469(1970)027<0580:TCIATI $>2.0$. CO;2.

Manganello, J. V., and Coauthors, 2012: Tropical cyclone climatology in a 10-km global atmospheric GCM: Toward weatherresolving climate modeling. J. Climate, 25, 3867-3893, https:// doi.org/10.1175/JCLI-D-11-00346.1.

Mendelsohn, R., K. Emanuel, S. Chonabayashi, and L. Bakkensen, 2012: The impact of climate change on global tropical cyclone damage. Nat. Climate Change, 2, 205, https://doi.org/10.1038/NCLIMATE1357.

Mohandas, S., and R. Ashrit, 2014: Sensitivity of different convective parameterization schemes on tropical cyclone prediction using a mesoscale model. Nat. Hazards, 73, 213-235, https://doi.org/10.1007/S11069-013-0824-6.

Mori, N., and Coauthors, 2019: 2018 Typhoon Jebi post-event survey of coastal damage in the Kansai region, Japan. Coast. Eng. J., 61, 278-294, https://doi.org/10.1080/21664250.2019.1619253. 
Murakami, H., and M. Sugi, 2010: Effect of model resolution on tropical cyclone climate projections. SOLA, 6, 73-76, https:// doi.org/10.2151/SOLA.2010-019.

,-- , and A. Kitoh, 2013: Future changes in tropical cyclone activity in the North Indian Ocean projected by high-resolution MRI-AGCMs. Climate Dyn., 40, 1949-1968, https://doi.org/ 10.1007/S00382-012-1407-Z.

Oh, S.-G., M.-S. Suh, D.-H. Cha, and S.-J. Choi, 2011: Simulation skills of RegCM4 for regional climate over CORDEX East Asia driven by HadGEM2-AO. J. Korean Earth Sci. Soc., 32, 732-749, http://doi.org/10.5467/JKESS.2011.32.7.732.

—, J.-H. Park, S.-H. Lee, and M.-S. Suh, 2014: Assessment of the RegCM4 over East Asia and future precipitation change adapted to the RCP scenarios. J. Geophys. Res. Atmos., 119, 2913-2927, https://doi.org/10.1002/2013JD020693.

Oouchi, K., J. Yoshimura, H. Yoshimura, R. Mizuta, S. Kusunoki, and A. Noda, 2006: Tropical cyclone climatology in a global-warming climate as simulated in a $20 \mathrm{~km}$-mesh global atmospheric model: Frequency and wind intensity analyses. J. Meteor. Soc. Japan, 84, 259-276, https://doi.org/10.2151/JMSJ.84.259.

Pal, J. S., E. E. Small, and E. A. B. Eltahir, 2000: Simulation of regional-scale water and energy budgets: Representation of subgrid cloud and precipitation processes within RegCM. J. Geophys. Res., 105, 29 579-29 594, https://doi.org/10.1029/2000JD900415.

Park, C., and Coauthors, 2016: Evaluation of multiple regional climate models for summer climate extremes over East Asia. Climate Dyn., 46, 2469-2486, https://doi.org/10.1007/S00382-015-2713-Z.

Park, D.-S. R., C.-H. Ho, and J.-H. Kim, 2014: Growing threat of intense tropical cyclones to East Asia over the period 19772010. Environ. Res. Lett., 9, 014008, https://doi.org/10.1088/ 1748-9326/9/1/014008.

,-- C. C. Nam, and H.-S. Kim, 2015: Evidence of reduced vulnerability to tropical cyclones in the Republic of Korea. Environ. Res. Lett., 10, 054003, https://doi.org/10.1088/17489326/10/5/054003.

Park, J.-H., S.-G. Oh, and M.-S. Suh, 2013: Impacts of boundary conditions on the precipitation simulation of RegCM4 in the CORDEX East Asia domain. J. Geophys. Res. Atmos., 118, 1652-1667, https://doi.org/10.1002/JGRD.50159.

Peduzzi, P., and Coauthors, 2012: Global trends in tropical cyclone risk. Nat. Climate Change, 2, 289, https://doi.org/10.1038/ NCLIMATE1410.

Redmond, G., K. I. Hodges, C. McSweeney, R. Jones, and D. Hein, 2015: Projected changes in tropical cyclones over Vietnam and the South China Sea using a $25 \mathrm{~km}$ regional climate model perturbed physics ensemble. Climate Dyn., 45, 1983-2000, https://doi.org/10.1007/S00382-014-2450-8.

Reisner, J., R. M. Rasmussen, and R. T. Bruintjes, 1998: Explicit forecasting of supercooled liquid water in winter storms using the MM5 mesoscale model. Quart. J. Roy. Meteor. Soc., 124, 1071-1107. https://doi.org/10.1002/qj.49712454804.

Shen, W., J. Tang, Y. Wang, S. Wang, and X. Niu, 2017: Evaluation of WRF model simulations of tropical cyclones in the western North Pacific over the CORDEX East Asia domain. Climate Dyn., 48, 2419-2435, https://doi.org/10.1007/S00382016-3213-5.

—_, J. Song, G. Liu, Y. Zhuang, Y. Wang, and J. Tang, 2019: The effect of convection scheme on tropical cyclones simulations over the CORDEX East Asia domain. Climate Dyn., 52, 46954713, https://doi.org/10.1007/S00382-018-4405-Y.

Shepherd, T. J., and K. J. Walsh, 2017: Sensitivity of hurricane track to cumulus parameterization schemes in the WRF model for three intense tropical cyclones: Impact of convective asymmetry.
Meteor. Atmos. Phys., 129, 345-374, https://doi.org/10.1007/ S00703-016-0472-Y.

Strachan, J., P. L. Vidale, K. Hodges, M. Roberts, and M.-E. Demory, 2013: Investigating global tropical cyclone activity with a hierarchy of AGCMs: The role of model resolution. J. Climate, 26, 133152, https://doi.org/10.1175/JCLI-D-12-00012.1.

Suh, M.-S., S.-G. Oh, D.-K. Lee, D.-H. Cha, S.-J. Choi, C.-S. Jin, and S.-Y. Hong, 2012: Development of new ensemble methods based on the performance skills of regional climate models over South Korea. J. Climate, 25, 7067-7082, https://doi.org/ 10.1175/JCLI-D-11-00457.1.

Tang, J., S. Wang, X. Niu, P. Hui, P. Zong, and X. Wang, 2017: Impact of spectral nudging on regional climate simulation over CORDEX East Asia using WRF. Climate Dyn., 48, 23392357, https://doi.org/10.1007/S00382-016-3208-2.

Vitart, F., J. Anderson, and W. Stern, 1997: Simulation of interannual variability of tropical storm frequency in an ensemble of GCM integrations. J. Climate, 10, 745-760, https://doi.org/ 10.1175/1520-0442(1997)010<0745:SOIVOT>2.0.CO;2.

von Storch, H., H. Langenberg, and F. Feser, 2000: A spectral nudging technique for dynamical downscaling purposes. Mon. Wea. Rev., 128, 3664-3673, https://doi.org/10.1175/1520-0493(2000)128<3664: ASNTFD $>2.0 . \mathrm{CO} ; 2$.

Walsh, K., S. Lavender, E. Scoccimarro, and H. Murakami, 2013: Resolution dependence of tropical cyclone formation in CMIP3 and finer resolution models. Climate Dyn., 40, 585599, https://doi.org/10.1007/S00382-012-1298-Z.

Wang, D., C. Menz, T. Simon, C. Simmer, and C. Ohlwein, 2013: Regional dynamical downscaling with CCLM over East Asia. Meteor. Atmos. Phys., 121, 39-53, https://doi.org/10.1007/S00703-013-0250-Z.

Wehner, M., and Coauthors, 2014: The effect of horizontal resolution on simulation quality in the Community Atmospheric Model, CAM5.1. J. Adv. Model. Earth Syst., 6, 980-997, https://doi.org/10.1002/2013MS000276.

- K. A. Reed, D. Stone, W. D. Collins, and J. Bacmeister, 2015: Resolution dependence of future tropical cyclone projections of CAM5.1 in the US CLIVAR Hurricane Working Group idealized configurations. J. Climate, 28, 3905-3925, https:// doi.org/10.1175/JCLI-D-14-00311.1.

Woodruff, J. D., J. L. Irish, and S. J. Camargo, 2013: Coastal flooding by tropical cyclones and sea-level rise. Nature, 504, 44-52, https://doi.org/10.1038/NATURE12855.

Yatagai, A., K. Kamiguchi, O. Arakawa, A. Hamada, N. Yasutomi, and A. Kitoh, 2012: APHRODITE: Constructing a long-term daily gridded precipitation dataset for Asia based on a dense network of rain gauges. Bull. Amer. Meteor. Soc., 93, 14011415, https://doi.org/10.1175/BAMS-D-11-00122.1.

Zhang, C., and Y. Wang, 2017: Projected future changes of tropical cyclone activity over the western North and South Pacific in a 20-km-mesh regional climate model. J. Climate, 30, 5923-5941, https://doi.org/10.1175/JCLI-D-16-0597.1.

Zhang, Q., L. Wu, and Q. Liu, 2009: Tropical cyclone damages in China 1983-2006. Bull. Amer. Meteor. Soc., 90, 489-496, https://doi.org/10.1175/2008BAMS2631.1.

Zhou, F., and M. Mu, 2012: The impact of horizontal resolution on the CNOP and on its identified sensitive areas for tropical cyclone predictions. Adv. Atmos. Sci., 29, 36-46, https:// doi.org/10.1007/S00376-011-1003-X.

Zou, L., T. Zhou, and D. Peng, 2016: Dynamical downscaling of historical climate over CORDEX East Asia domain: A comparison of regional ocean-atmosphere coupled model to stand-alone RCM simulations. J. Geophys. Res. Atmos., 121, 1442-1458, https://doi.org/10.1002/2015JD023912. 